\title{
A Library Approach to the Development of BenzaPhos: Highly Efficient Chiral Supramolecular Ligands for Asymmetric Hydrogenation
}

\author{
Luca Pignataro, ${ }^{*[a]}$ Chiara Bovio, ${ }^{[a]}$ Monica Civera, ${ }^{[a]}$ Umberto Piarulli, ${ }^{[b]}$ and \\ Cesare Gennari*[a]
}

\begin{abstract}
A library of chiral supramolecular ligands, named BenzaPhos, of straightforward preparation (two steps from commercially or readily available starting materials) and modular structure, was designed and synthesized. The ligands were screened in the search for new rhodium catalysts for the enantioselective hydrogenation of several benchmark and industrially relevant substrates. Once a series of hits were identified, structural modifications were introduced on three of the best ligands and a small second-genera-
\end{abstract}

tion library was created. Members of the latter library showed outstanding levels of activity and enantioselectivity in the hydrogenation of challenging olefins, such as enamide $\mathbf{S 4}$ and $\beta$-dehydroamino ester S5 (>99\% ee: best value ever reported in both cases). A series of control experiments were un-

Keywords: asymmetric catalysis combinatorial catalysis - hydrogen bonds - substrate orientation . supramolecular chemistry

\begin{abstract}
dertaken to clarify the role of hydrogen bonding in determining the catalytic properties of the new ligands. The results of these experiments, together with those of computational studies carried out on four dihydride complexes involved in the catalytic hydrogenation of substrate $\mathbf{S 4}$, strongly suggest that a substrate orientation takes place in the catalytic cycle by formation of a hydrogen bond between the ligand amide oxygen atom and the substrate amide $\mathrm{NH}$ atom.
\end{abstract}

\section{Introduction}

During its fifty-year-long history, asymmetric homogeneous catalysis has progressed enormously, and highly enantioselective catalysts have been discovered for many important organic transformations. ${ }^{[1]}$ The fast-growing social demand for enantiopure compounds-especially in the manufacture of pharmaceutical products-has certainly been a potent stimulus for such development, catalytic methodologies being in principle the most direct and atom-economical way to perform an enantioselective reaction. Despite this, asymmetric catalysis has not yet established itself as the methodology of choice for the industrial preparation of enantiopure compounds, most of which are still obtained from the classical resolution of diastereomeric salts. ${ }^{[2]}$ Two important reas-

[a] Dr. L. Pignataro, C. Bovio, Dr. M. Civera, Prof. Dr. C. Gennari Università degli Studi di Milano

Dipartimento di Chimica Organica e Industriale

Istituto di Scienze e Tecnologie Molecolari (ISTM) del CNR

Via G. Venezian, 21, 20133, Milano (Italy)

Fax: $(+39) 02-50314072$

E-mail: luca.pignataro@unimi.it cesare.gennari@unimi.it

[b] Prof. Dr. U. Piarulli

Università degli Studi dell'Insubria

Dipartimento di Scienza e Alta Tecnologia

Via Valleggio, 11, 22100, Como (Italy)

Fax: (+39) 031-2386449

E-mail: umberto.piarulli@uninsubria.it

Supporting information for this article is available on the WWW under http://dx.doi.org/10.1002/chem.201201032. ons for this paradoxical situation are 1) the strong time-tomarket pressure present in the pharmaceutical industry, which does not allow sufficient time for the development of a catalytic process and 2) the high cost of the chiral catalysts employed. A combinatorial approach to catalysis ${ }^{[3]}$ may tackle both of these issues by allowing libraries of ligands/ catalysts to be quickly tested (by high-throughput screening) to identify efficient enantioselective catalysts for a selected substrate. A fundamental requisite for this is that the ligands/catalysts can be readily accessed and are of low cost, so that relatively large libraries can be prepared and screened in a short time. Chiral monodentate $\mathrm{P}$ ligands, the rediscovery of which started some fifteen years ago, ${ }^{[4]}$ are excellent candidates for combinatorial screening strategies in asymmetric transition-metal catalysis, because of the following general features: 1) they are simpler to prepare than bidentate ligands, while securing in many cases similar or even better levels of stereocontrol; 2) they often have a modular structure, which facilitates the introduction of structural diversity into the library; and 3 ) the use of binary mixtures of monodentate ligands in the presence of a transition-metal source allows further expansion of the combinatorial space, the complexes obtained from ligand combinations often being more enantioselective than the complex of each separate ligand. ${ }^{[5]}$

Alongside a renewed interest in chiral monodentate ligands, the last decade has also seen a growing interest in supramolecular transition-metal catalysis. ${ }^{[6]}$ Accordingly, ligands have been developed that possess, aside from the atom coordinating to the catalytic metal, an additional functionali- 


\section{A. PhthalaPhos ligands}

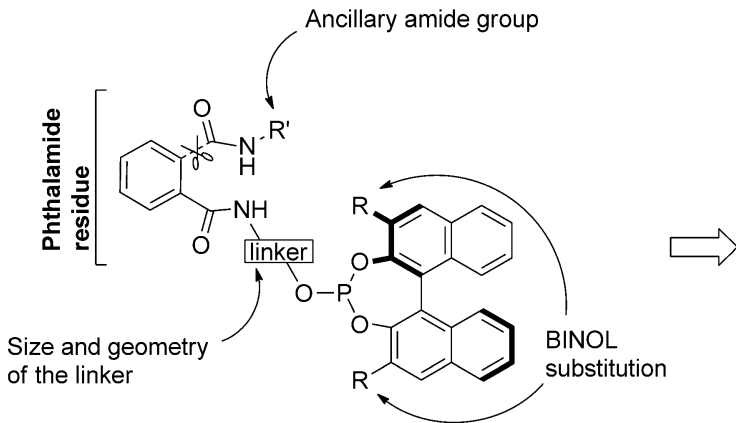

B. BenzaPhos ligands

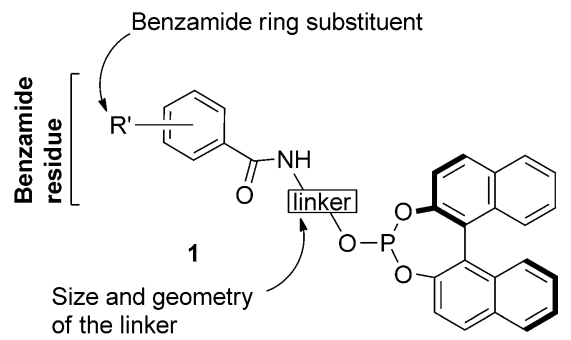

Scheme 1. Conception of BenzaPhos (B) from PhthalaPhos ligands (A). Curved arrows indicate possible points of diversification.

ty capable of either ligand-ligand or ligand-substrate noncovalent interactions. These supramolecular constructs display improved catalytic performances (i.e., activity and regioand/or stereoselectivity) compared to those obtained with simple monodentate ligands. Unfortunately, in many cases the penalty for installing a second functional group capable of noncovalent interactions consists of increasing the structural complexity of the ligands and, consequently, the synthetic effort required for their preparation. Therefore, the creation of new classes of chiral ligands with simple structures and very easy methods of preparation is the condition for supramolecular catalysis to become of practical industrial use.

Our research group has a longstanding interest in catalytic enantioselective methodologies based on both simple monodentate $^{[7]}$ and supramolecular ligands, ${ }^{[8]}$ and has recently developed a new class of highly efficient chiral ligands, called PhthalaPhos ligands, for the Rh-catalyzed asymmetric hydrogenation of olefins. ${ }^{[9]}$ The PhthalaPhos ligands are $1,1^{\prime}$ bi-2-naphthol (BINOL)-derived phosphites capable of exerting a substrate-orientating effect by hydrogen bonding, ${ }^{[9 \mathrm{~b}]}$ which makes them significantly more enantioselective than structurally related monofunctional ligands. Although PhthalaPhos ligands have simpler structures and are easier to prepare than other supramolecular ligands ${ }^{[6]}$ (they can be synthesized in four steps from inexpensive commercial products), we sought to further simplify their structure while preserving the ability to orientate the reaction substrate in the hydrogenation process.

Herein, we describe our efforts in this direction, which resulted in the creation of a new class of chiral supramolecular BINOL-derived phosphites, called BenzaPhos, prepared in only two linear steps from readily available or commercial starting materials and are therefore well-suited for a library approach to the discovery of effective catalysts. The new ligands were screened in the $\mathrm{Rh}$-catalyzed asymmetric hydrogenation of olefins, and optimized by taking advantage of their modular structure. Control experiments and computational studies were carried out to assess whether the role of the amide group also consists of a substrate-orientating effect in this case.

\section{Results and Discussion}

Ligand design: As shown in Scheme 1, the BenzaPhos ligands (1) are conceptually derived from the PhthalaPhos ligands, ${ }^{[9]}$ the ancillary amide group of which (i.e., the amide group that is not connected to the phosphite residue) has been removed. This modification has two important consequences: 1) as discussed in more detail below, the ligand synthesis is significantly shortened, the BenzaPhos ligands being simple benzoic acid derivatives that are prepared in only two steps from an aminoalcohol; and 2) the BenzaPhos ligands have only one functional group capable of forming

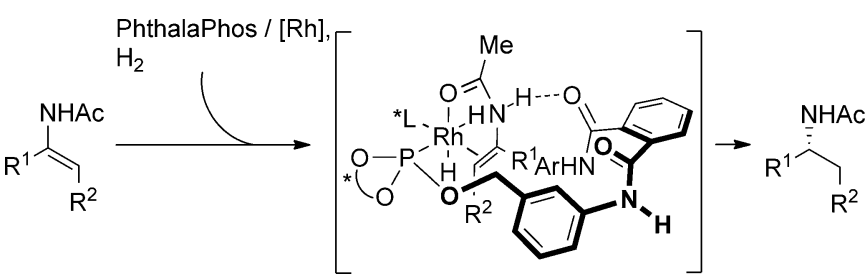

Scheme 2. Substrate orientation by hydrogen bonding proposed for the PhthalaPhos ligands. ${ }^{[9 b]}$

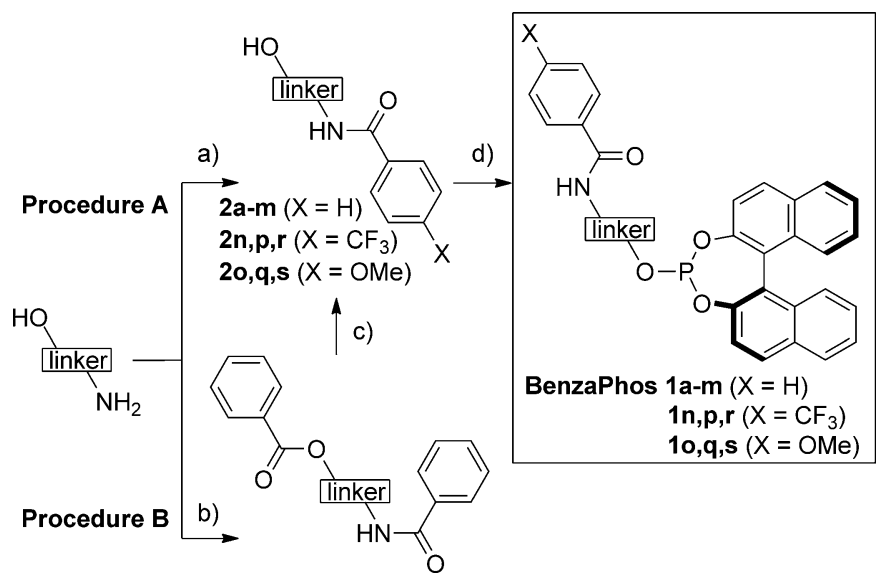

Scheme 3. Synthesis of BenzaPhos ligands. Procedure A for $N$-benzoylation: a) benzoyl chloride, 4-(trifluoromethyl)benzoyl chloride, or 4-(methoxy)benzoyl chloride (1 equiv), triethylamine (TEA), $0^{\circ} \mathrm{C}$ to RT, $45-92 \%$. Procedure B for $N$-benzoylation: b) benzoyl chloride (3 equiv), TEA, THF, RT; c) LiOH $\cdot \mathrm{H}_{2} \mathrm{O}, 4: 1 \mathrm{THF} / \mathrm{H}_{2} \mathrm{O}, \mathrm{RT}, 39-83 \%$ (two steps). Formation of the BINOL phosphite: d) (S)-BINOL-PCl, TEA, THF, RT, $41-80 \%$. 
strong hydrogen bonds and, remarkably, they lack the very amide group that - according to our studies ${ }^{[9]}$ — is involved in substrate orientation in the case of the PhthalaPhos ligands (Scheme 2).

To showcase the potential of BenzaPhos ligands in the combinatorial search for new catalysts, a library of $(S)$ BINOL-derived phosphite ligands was prepared, containing an unsubstituted benzamide group $\left(\mathrm{R}^{\prime}=\mathrm{H}\right.$, see Scheme $\left.1 \mathrm{~B}\right)$ and differing only in the linker (the first-generation library). Once a few hits were identified in the asymmetric Rh-catalyzed hydrogenation, variation of the benzamide substitution pattern was performed with the aim of optimizing the results (the second-generation library). We decided not to vary the BINOL substitution because our previous data showed that the presence of substituents at the $3,3^{\prime}$ position is detrimental to the catalytic activity in the hydrogenation process. $^{[9]}$

Preparation of the BenzaPhos ligand library: The ligands (1a-s, Scheme 3) were prepared in two steps from simple aminoalcohols, which were $N$-benzoylated (39-83\% yield) and then reacted with $(S)$-BINOL-derived chlorophos-<smiles>O=C(Nc1cccc(OP(Oc2cccc3ccccc23)Oc2cccc3ccccc23)c1)c1ccccc1</smiles><smiles>O=C(NCCc1cccc(Op2oc3ccc4ccccc4c3c3c(ccc4ccccc43)op(Oc3ccccc3)o2)c1)c1ccccc1</smiles><smiles>O=C(NCc1ccc(COp2oc3ccc4ccccc4c3c3c(ccc4ccccc43)o2)cc1)c1ccccc1</smiles>

$1 \mathrm{~g}$<smiles>O=C(Nc1cccc(COp2oc3ccc4ccccc4c3c3c(ccc4ccccc43)o2)c1)c1ccccc1</smiles>

1b<smiles>O=C(NCCc1cccc(COP2Oc3ccc4ccccc4c3C3=C2C=CC=C2C=CC=C3O2)c1)c1ccccc1</smiles>

$1 e$<smiles>O=C(NCCc1ccc(COP(O)Oc2ccc3ccccc3c2-c2c(OP(OCc3ccccc3)c3ccccc3)ccc3ccccc23)cc1)c1ccccc1</smiles><smiles>O=C(NCc1cccc(COP2Oc3ccc4ccccc4c3C(c3cccc4ccccc34)O2)c1)c1ccccc1</smiles>

$1 c$<smiles>O=C(Nc1ccc(COP2Oc3ccc4ccccc4c3-c3c2ccc2ccccc32)cc1)c1ccccc1</smiles>

$1 f$

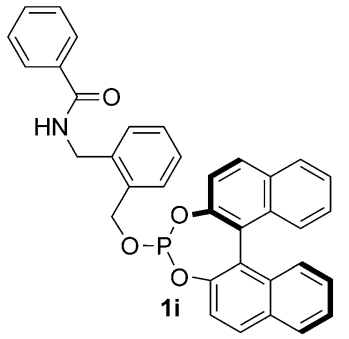<smiles>O=C(NCCc1ccccc1COp1oc2ccc3ccccc3c2c2c(ccc3ccccc32)o1)c1ccccc1</smiles><smiles>CC(C)(CNC(=O)c1ccccc1)COp1oc2ccc3ccccc3c2c2c(ccc3ccccc32)o1</smiles>

$1 \mathrm{k}$

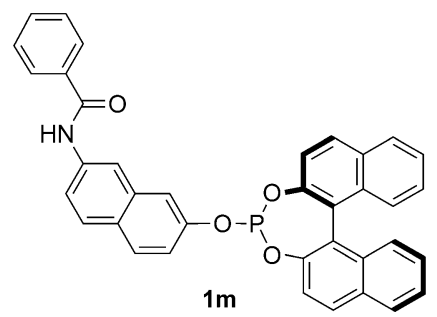

Figure 1. The first-generation BenzaPhos ligand library. 
phite $^{[10]}$ (41-80\% yield). Some of the aminoalcohols are commercially available, whereas the others were easily prepared according to known methods. ${ }^{[9 b]}$

The aminoalcohols were $N$ benzoylated by using two different procedures, depending on the relative nucleophilic strength of the amino and hydroxy functionalities (Scheme 3). Substrates possessing an aliphatic $\mathrm{OH}$ group were selectively $N$-benzoylated (with one exception) in the presence of benzoyl chloride [or 4-(trifluoromethyl)benzoyl chloride or 4-(methoxy)benzoyl chloride; 1 equiv] to yield alcohols 2 (procedure A). Amino alcohols possessing a phenolic $\mathrm{OH}$ group could not be selectively $N$-benzoylated and yielded mixtures of $\mathrm{N}$-benzoylated, $\mathrm{O}$-benzoylated, and bis(benzoylated) products. Consequently, these aminoalcohols were bis(benzoylated) in the presence of benzoyl chloride ( 3 equiv), and the ester group in the resulting crude amidoesters was selectively saponified to yield the corresponding alcohols (procedure B).

Catalytic screening of the first-generation library: The firstgeneration ligand library, shown in Figure $1(\mathbf{1} \mathbf{a}-\mathbf{m})$, was screened in the rhodium-catalyzed enantioselective hydrogenation of six prochiral olefins: three classical benchmark substrates, that is, methyl 2-acetamidoacrylate (S1), methyl (Z)-2-acetamidocinnamate (S2), and $N$-(1phenylvinyl)acetamide (S3), and three challenging, industrially relevant ${ }^{[11]}$ substrates, that is, cyclic enamide $\mathbf{S 4}[N-(3,4-$ dihydronaphthalen-1-yl)acetamide], $\beta^{2}$-dehydro aminoester S5 [(E)-methyl 2-(acetamidomethyl)-3-phenylacrylate], and the Roche ester precursor S6 [methyl 2-(hydroxymethyl)acrylate]. Phenyl phosphite $\mathbf{3} \mathbf{a}^{[12]}$ and benzyl phosphite $\mathbf{3} \mathbf{b}^{[13]}$ (Figure 2)-two simple monodentate BINOL-phosphites
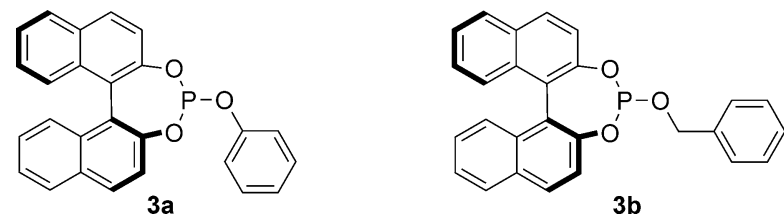

Figure 2. Monodentate phosphites employed as reference compounds in the catalytic screening.

that are structurally related to the BenzaPhos ligands, but devoid of functional groups capable of supramolecular interactions-were also screened with the same substrates to provide a reference for evaluating the effect of the benzamide group on the catalytic behavior of ligands $\mathbf{1}$. The best results obtained with each substrate are shown in Tables 1-6. The full set of results is graphically represented in Figure 3, and tabulated in the Supporting Information.

The library screening in the hydrogenation of methyl 2acetamidoacrylate S1 (Table 1 and Figure 3) gave encouraging results, with six ligands affording $>94 \% e e$, three of which afforded $>97 \%$ ee. The importance of a properly positioned benzamide group is revealed by the following observations: 1) the length and geometry of the linker group of ligands 1 proved crucial for obtaining a high level of stereocontrol (see the Supporting Information for the com-

Table 1. Selected results of the screening of the first-generation BenzaPhos library in the enantioselective hydrogenation of methyl 2-acetamidoacrylate S1. ${ }^{[a]}$

\begin{tabular}{|c|c|c|c|}
\hline & $\int_{\mathrm{s} 1}^{\mathrm{NHAc}} \mathrm{CO}$ & $\begin{array}{l}\stackrel{\mathrm{H}_{2}(1 \mathrm{bar}),}{\mathrm{Rh}(\mathrm{cod})_{2} \mathrm{BF}_{4} / \mathrm{L}} \\
\mathrm{CH}_{2} \mathrm{Cl}_{2}, \mathrm{RT}, 20 \mathrm{~h}\end{array}$ & \\
\hline & Ligand & Conv. $[\%]^{[\mathrm{b}]}$ & $\begin{array}{l}e e[\%],{ }^{[\mathrm{b}]} \\
\text { abs. conf. }\end{array}$ \\
\hline 1 & $1 \mathrm{~b}$ & 100 & $99, R$ \\
\hline 2 & $1 \mathrm{c}$ & 100 & $99, R$ \\
\hline 3 & $1 \mathrm{e}$ & 100 & $98, R$ \\
\hline 4 & $\mathbf{1 i}$ & 100 & $97, R$ \\
\hline 5 & $\mathbf{1 j}$ & 100 & $97, R$ \\
\hline 6 & $1 \mathbf{k}$ & 100 & $96, R$ \\
\hline 7 & $3 \mathbf{a}$ & 100 & $84, R$ \\
\hline 8 & $\mathbf{3 b}$ & 100 & $90, R$ \\
\hline
\end{tabular}

[a] Reaction conditions: substrate/ligand/[Rh( $\left.\operatorname{cod})_{2} \mathrm{BF}_{4}\right]=100: 2.2: 1$, solvent $=\mathrm{CH}_{2} \mathrm{Cl}_{2}, c_{0}(\mathbf{S 1})=0.048 \mathrm{M}, T=25^{\circ} \mathrm{C}$. [b] Determined by $\mathrm{GC}$ with a chiral capillary column (MEGADEX DACTBS $\beta$, diacetyl-tert-butylsilyl- $\beta$-cyclodextrin; Conv. = conversion). [c] Assignment based on the GC retention times, by comparison with the results obtained with $\mathbf{3 a}$, the stereochemical preference of which is known (abs. conf. $=$ absolute configuration). ${ }^{[12]}$ 
plete set of data), and 2) reference ligands $\mathbf{3 a}$ and $\mathbf{3 b}$ gave lower $e e$ values ( 84 and $90 \% e e$, respectively).

Very good results were also obtained in the screening of benchmark substrates S2 and S3. With the former alkene (best results shown in Table 2), six ligands gave $>94 \%$ ee, one of which ligand gave $>99 \% e e e^{[14]}$ whereas the reference phosphites $\mathbf{3 a}$ and $\mathbf{3 b}$ afforded only 70 and $83 \% e e$, respectively. With enamide $\mathbf{S 3}$ (best results shown in Table 3), eight ligands gave $>94 \% e e$, three of which gave $>97 \% e e$, whereas the reference ligands $3 \mathbf{a}$ and $\mathbf{3 b}$ gave 90 and $94 \% e e$, respectively. Therefore, also in this case the presence of the benzamide group enhances the stereocontrol, provided that the linker is suitable.

Table 2. Selected results of the screening of the first-generation BenzaPhos library in the enantioselective hydrogenation of methyl (Z)-2-acetamidocinnamate $\mathbf{S 2}$. ${ }^{[a]}$

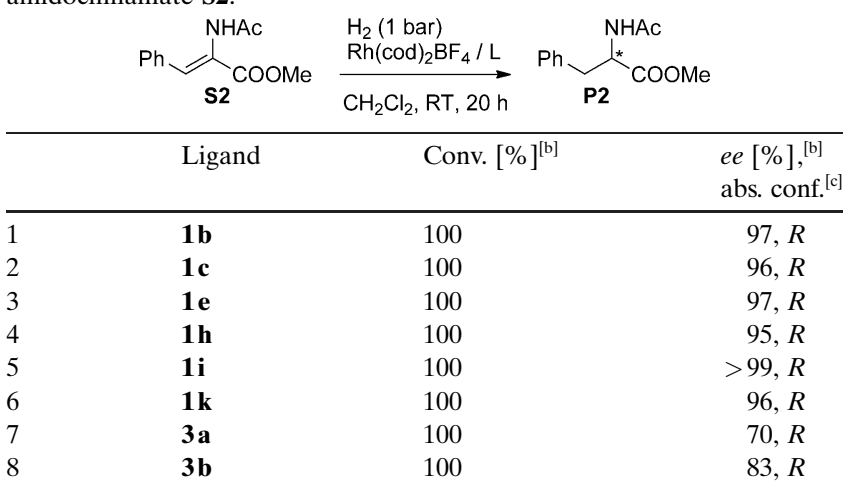

[a] Reaction conditions: substrate/ligand/[Rh( $\left.\operatorname{cod})_{2} \mathrm{BF}_{4}\right]=100: 2.2: 1$, solvent $=\mathrm{CH}_{2} \mathrm{Cl}_{2}, c_{0}(\mathbf{S 2})=0.048 \mathrm{M}, P=1$ bar, $T=25^{\circ} \mathrm{C}$. [b] Conversion determined by ${ }^{1} \mathrm{H}$ NMR spectroscopy on the crude reaction mixture; $e e$ determined by HPLC with a chiral column (Daicel Chiralpak AD-H). [c] Assigned by comparison of the sign of the optical rotation with literature data. ${ }^{[14]}$

Table 3. Selected results of the screening of the first-generation BenzaPhos library in the enantioselective hydrogenation of $N$-(1-phenylvinyl)acetamide $\mathbf{S 3}{ }^{[\mathrm{a}]}$

$$
\int_{\mathrm{S} 3}^{\mathrm{NHAc}} \mathrm{Ph} \underset{\mathrm{CH}_{2} \mathrm{Cl}_{2}, \mathrm{RT}, 20 \mathrm{~h}}{\stackrel{\mathrm{Rh}_{2}(\mathrm{cod})_{2} \mathrm{BF}_{4} / \mathrm{L}}{\longrightarrow}} \overbrace{\mathrm{P} 3}^{\mathrm{NHAc}} \mathrm{Ph}
$$

\begin{tabular}{rlcc}
\hline & Ligand & Conv. $[\%]^{[\mathrm{b}]}$ & $\begin{array}{c}e e[\%]{ }^{[\mathrm{b}]} \\
\text { abs. conf. }{ }^{[\mathrm{c}]}\end{array}$ \\
\hline 1 & $\mathbf{1 b}$ & 100 & $99, R$ \\
2 & $\mathbf{1 c}$ & 100 & $>99, R$ \\
3 & $\mathbf{1 e}$ & 100 & $97, R$ \\
4 & $\mathbf{1 ~ f}$ & 100 & $95, R$ \\
5 & $\mathbf{1 g}$ & 100 & $99, R$ \\
6 & $\mathbf{1 i}$ & 100 & $97, R$ \\
7 & $\mathbf{1 j}$ & 100 & $97, R$ \\
8 & $\mathbf{1 k}$ & 100 & $96, R$ \\
9 & $\mathbf{3 a}$ & 100 & $90, R$ \\
10 & $\mathbf{3 b}$ & 100 & $94, R$ \\
\hline
\end{tabular}

[a] Reaction conditions: substrate/ligand/[Rh( $\left.\operatorname{cod})_{2} \mathrm{BF}_{4}\right]=100: 2.2: 1$, solvent $=\mathrm{CH}_{2} \mathrm{Cl}_{2}, c_{0}(\mathbf{S 3})=0.024 \mathrm{M}, P=5 \mathrm{bar}, T=25^{\circ} \mathrm{C}$. [b] Determined by GC with a chiral capillary column (MEGADEX DACTBS $\beta$, diacetyl-tertbutylsilyl- $\beta$-cyclodextrin). [c] Assignment based on the GC retention times, by comparison with the results obtained with $\mathbf{3 a}$, the stereochemical preference of which is known. ${ }^{[12,13]}$
The effect of the linker is also evident in the hydrogenation of challenging substrates, for which remarkably diverse levels of stereocontrol were obtained with different members of the ligand library. As shown in Table $4,{ }^{[15]}$ several ligands gave very good stereocontrol in the hydrogenation of substrate S4 (under 20 bar hydrogen pressure), equaling in two cases (Table 4, entries 2 and 3 ) the best ee value ( $98 \%$ ee) reported in the literature for employing a monodentate $\left(\text { at }-20^{\circ} \mathrm{C}\right)^{[16]}$ or bidentate ligand (at RT). ${ }^{[17]}$ Also in this case, the reference ligands $\mathbf{3} \mathbf{a}$ and $\mathbf{3 b}$ proved less enantioselective than the best members of our library, although a respectable $96 \%$ ee was obtained with $\mathbf{3 b}$.

The screening of the ligand library with olefin $\mathbf{S 5}$ (Table 5$)^{[18]}$ required a hydrogen pressure of $50 \mathrm{bar}$, due to the poor reactivity of this substrate. Both $e e$ and conversion values ranged widely, but appeared to be correlated, the

Table 4. Selected results of the screening of the first-generation BenzaPhos library in the enantioselective hydrogenation of $N$-(3,4-dihydronaphthalen-1-yl)acetamide $\mathbf{S 4} .^{\text {[a] }}$

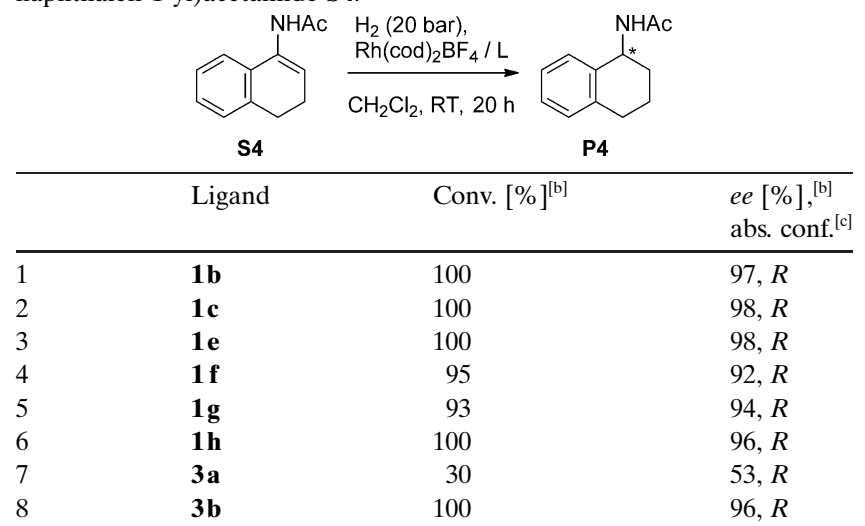

[a] Reaction conditions: substrate/ligand/[Rh( $\left.\operatorname{cod})_{2} \mathrm{BF}_{4}\right]=100: 2.2: 1$, solvent $=\mathrm{CH}_{2} \mathrm{Cl}_{2}, c_{0}(\mathbf{S} 4)=0.024 \mathrm{M}, P=20 \mathrm{bar}, T=25^{\circ} \mathrm{C}$. [b] Determined by GC with a chiral capillary column (MEGADEX DACTBS $\beta$, diacetyl-tertbutylsilyl- $\beta$-cyclodextrin). [c] Assigned by comparison of the sign of the optical rotation with literature data. ${ }^{[15]}$

Table 5. Selected results of the screening of the first-generation BenzaPhos library in the enantioselective hydrogenation of $(E)$-methyl 2-(acetamidomethyl)-3-phenylacrylate $\mathbf{S 5}^{\text {[a] }}$

\begin{tabular}{|c|c|c|c|}
\hline & ${ }^{\mathrm{NHAc}} \mathrm{CO}$ & $\begin{array}{l}\mathrm{H}_{2}(50 \text { bar), } \\
\mathrm{Rh}(\mathrm{cod})_{2} \mathrm{BF}_{4} / \mathrm{L}\end{array}$ & \\
\hline & Ligand & Conv. $[\%]^{[\mathrm{b}]}$ & $\begin{array}{l}e e[\%],{ }^{[\mathrm{b}]} \\
\text { abs. conf. }{ }^{[\mathrm{c}]}\end{array}$ \\
\hline 1 & $1 \mathrm{~b}$ & 35 & $93, R$ \\
\hline 2 & 1c & 62 & $>99, R$ \\
\hline 3 & $1 \mathrm{e}$ & 30 & $86, R$ \\
\hline 4 & $1 \mathrm{~g}$ & 94 & $>99, R$ \\
\hline 5 & $1 \mathrm{~h}$ & 43 & $>99, R$ \\
\hline 6 & $3 \mathbf{a}$ & 6 & $32, R$ \\
\hline 7 & $3 \mathbf{b}$ & 37 & $90, R$ \\
\hline
\end{tabular}

[a] Reaction conditions: substrate/ligand/[Rh( $\left.\operatorname{cod})_{2} \mathrm{BF}_{4}\right]=100: 2.2: 1$, solvent $=\mathrm{CH}_{2} \mathrm{Cl}_{2}, c_{0}(\mathbf{S 5})=0.024 \mathrm{M}, P=50$ bar, $T=25^{\circ} \mathrm{C}$. [b] Determined by GC with a chiral capillary column (MEGADEX DACTBS $\beta$, diacetyl-tertbutylsilyl- $\beta$-cyclodextrin). [c] Assigned by comparison of the sign of the optical rotation with literature data. ${ }^{[18]}$ 
most stereoselective ligands giving higher conversions. Ligands $\mathbf{1 c}, \mathbf{1 g}$, and $\mathbf{1 h}$ (Table 5, entries 2, 4, and 5) gave very high ee values (>99\%), comparable with the best results obtained with the PhthalaPhos ligands (i.e., the highest enantiomeric excess ever reported for substrate S5). ${ }^{[9]} \mathrm{Un}$ fortunately, the conversion was never complete. Lower ee values and conversions were again obtained with the reference ligands 3a and $\mathbf{3 b}$ (Table 5, entries 6 and 7), the latter being more enantioselective than the former.

Finally, the library was screened in the hydrogenation of the Roche ester precursor S6 under 50 bar hydrogen pressure. As with the other substrates, conversion and $e e$ values with S6 ranged widely depending on the ligand used (see the Supporting Information for the complete set of data). In several cases (see Table 6), full conversion and good ee values $^{[19]}$ were obtained, although these never exceeded $87 \%$ ee (Table 6, entry 4). The reference ligands $\mathbf{3 a}$ and $\mathbf{3 b}$ gave 64 and $85 \%$ ee (Table 6, entry 6 and 7), respectively.

Table 6. Selected results of the screening of the first-generation BenzaPhos library in the enantioselective hydrogenation of methyl 2-(hydroxymethyl)acrylate $\mathbf{S 6}$ (the Roche ester precursor). ${ }^{[a]}$

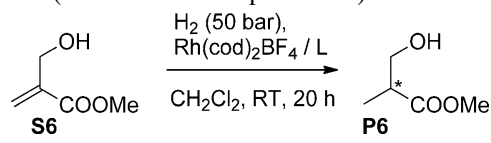

\begin{tabular}{llll}
\hline & Ligand & Conv. $[\%]^{[\mathrm{b}]}$ & $\begin{array}{l}e e[\%]{ }^{[\mathrm{b}]} \\
\text { abs. conf. }{ }^{[\mathrm{c}]}\end{array}$ \\
\hline 1 & $\mathbf{1 b}$ & 100 & $85, S$ \\
2 & $\mathbf{1 c}$ & 100 & $84, S$ \\
3 & $\mathbf{1 e}$ & 100 & $76, S$ \\
4 & $\mathbf{1 g}$ & 100 & $87, S$ \\
5 & $\mathbf{1 h}$ & 100 & $86, S$ \\
6 & $\mathbf{3 a}$ & 100 & $64, S$ \\
7 & 3b & 100 & $85, S$ \\
\hline
\end{tabular}

[a] Reaction conditions: substrate/ligand/[Rh( $\left.\operatorname{cod})_{2} \mathrm{BF}_{4}\right]=100: 2.2: 1$, solvent $=\mathrm{CH}_{2} \mathrm{Cl}_{2}, \quad c_{0} \quad(\mathbf{S 6})=0.024 \mathrm{M}, P=50$ bar, $T=25^{\circ} \mathrm{C}$. [b] Conversion determined by ${ }^{1} \mathrm{H}$ NMR spectroscopy on the crude reaction mixture; $e e$ determined on the 4-nitrobenzoic acid ester derivative by HPLC with $\mathrm{F}_{3} \mathrm{C}$ a chiral column (Daicel Chiralpak AD-H). [c] Assigned by comparison of the sign of the optical rotation with literature data. ${ }^{[19]}$

The full set of results for the catalytic screening with substrates S1-S6 is graphically depicted in Figure 3. From this synopsis, the following comments can be made:

1) For all substrates, the use of BenzaPhos ligands leads to a remarkable improvement, in terms of activity and stereocontrol, compared with that observed with simple monodentate phosphites. Although always present, such an improvement is generally more evident with reference to $\mathbf{3 a}$ than $\mathbf{3 b}$.

2) There is a larger number of highly effective ligands for the hydrogenation of benchmark substrates (S1, S2, and S3) than for challenging olefins (S4, S5, and S6).

3) The best performing ligands are not the same for all substrates, which underlines the value of the library ap- proach. In particular, the nature of the linker appears to strongly affect the catalytic behavior of the ligands.

4) The ligands featuring rigid linker groups (1a, 1l, and $1 \mathbf{m})$ behave poorly in all cases, showing lower levels of activity and stereoselectivity.

On the basis of the screening described above, we selected three highly effective ligands $(\mathbf{1 b}, \mathbf{1 c}$, and $\mathbf{1 g})$ for further optimization by varying the benzamide group.

Second-generation ligands: Six second-generation ligands (1n-s, Figure 4) were designed by replacing the benzamide residue of ligands $\mathbf{1 b}, \mathbf{1 c}$, and $\mathbf{1 g}$ with a 4-(trifluoromethyl)benzamide and a 4-(methoxy)benzamide group. The synthesis of the new ligands was carried out by following the twostep protocol shown in Scheme 3 (procedure A), replacing benzoyl chloride with commercially available 4-(trifluoromethyl)benzoyl chloride and 4-(methoxy)benzoyl chloride (yield of the $N$-benzoylation $=60-92 \%$; yield of the phosphite synthesis $=48-74 \%$ ).
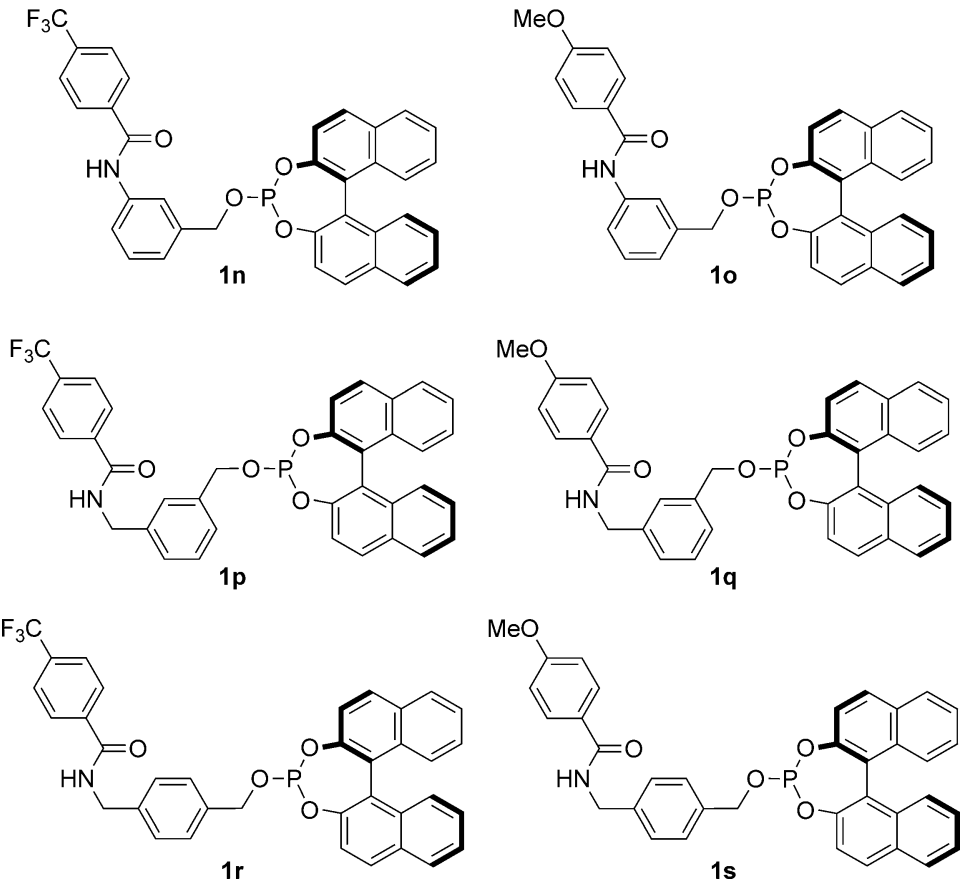

Figure 4. Second-generation BenzaPhos ligands (featuring a 4-substituted benzamide group).

The second-generation ligands $\mathbf{1} \mathbf{n}-\mathbf{s}$ were screened in the hydrogenation of substrates S1-S6. From the results of the screening, shown in Table 7, the following comments can be made:

1) The presence of a substituted benzamide group led to a significant improvement in the stereoselectivity (compared to the parent ligands $\mathbf{1 b}, \mathbf{1 c}$, and $\mathbf{1 g}$, featuring the same linker) in the hydrogenation of substrates S2, S4, and S6. In the first case, both ligand $\mathbf{1 p}(99 \% e e)$ and $\mathbf{1 q}$ 
Table 7. Second-generation ligand (1n-s) screening in the hydrogenation of substrates S1-S6. ${ }^{\text {[a] }}$

\begin{tabular}{|c|c|c|c|c|c|c|c|c|c|}
\hline Parent ligand & Ligand used & $\begin{array}{l}\mathbf{S 1}^{[\mathrm{b}, \mathrm{c}]} \\
e e[\%] \\
\text { abs. conf. }\end{array}$ & $\begin{array}{l}\mathbf{S 2}^{[\mathrm{b}, \mathrm{c}]} \\
e e[\%] \\
\text { abs. conf. }\end{array}$ & $\begin{array}{l}\mathbf{S 3}^{[\mathrm{b}, \mathrm{c}]} \\
e e[\%], \\
\text { abs. conf. }\end{array}$ & $\begin{array}{l}\mathbf{S 4}^{[\mathrm{b}]} \\
\text { Conv. } \\
{[\%]}\end{array}$ & $\begin{array}{l}e e[\%], \\
\text { abs. conf. }\end{array}$ & $\begin{array}{l}\mathbf{S 5}^{[\mathrm{b}]} \\
\text { Conv. } \\
{[\%]} \\
\end{array}$ & $\begin{array}{l}e e[\%], \\
\text { abs. conf. }\end{array}$ & $\begin{array}{l}\mathbf{S 6}^{[\mathrm{b}, \mathrm{c}]} \\
e e[\%], \\
\text { abs. conf. }\end{array}$ \\
\hline \multirow{2}{*}{$1 \mathbf{b}$} & $1 n$ & $98, R$ & $89, R$ & $98, R$ & 92 & $91, R$ & 27 & $55, R$ & $87, S$ \\
\hline & 10 & $97, R$ & $96, R$ & $99, R$ & 57 & $84, R$ & 57 & $76, R$ & $87, S$ \\
\hline \multirow{2}{*}{$1 \mathrm{c}$} & $1 \mathbf{p}$ & $97, R$ & 99, $R$ & $99, R$ & 100 & $>99, R$ & 28 & $90, R$ & $85, S$ \\
\hline & $1 q$ & $97, R$ & $98, R$ & $>99, R$ & 100 & 99, $R$ & 44 & $92, R$ & $88, S$ \\
\hline \multirow{2}{*}{$1 \mathrm{~g}$} & $1 \mathbf{r}$ & $91, R$ & $82, R$ & $98, R$ & 100 & 97, $R$ & 70 & $82, R$ & $86, S$ \\
\hline & $1 \mathrm{~s}$ & $91, R$ & $82, R$ & $97, R$ & 83 & 96, $R$ & 100 & $>99, R$ & $86, S$ \\
\hline
\end{tabular}

[a] Improvements compared with the parent (first-generation) ligands (i.e., featuring the same linker) are highlighted with boldface characters. [b] For reaction and ee determination conditions in the hydrogenation of S1, S2, S3, S4, S5, and S6, see the footnotes of Tables 1, 2, 3, 4, 5, and 6, respectively. [c] Conversion $=100 \%$ in all cases.

(98\% ee) proved more enantioselective than the parent ligand $\mathbf{1 c}$. In the hydrogenation of $\mathbf{S 4}$, ligand $\mathbf{1 p}$ afforded $>99 \% e e$, which is the highest $e e$ value ever reported for this cyclic enamide. ${ }^{[9,16,17]}$ Furthermore, ligands 1q, 1r, and $\mathbf{1 s}$ proved more enantioselective than their first-generation counterparts (1c and $\mathbf{1 g}$ ). In the case of S6, ligand $\mathbf{1 q}$ afforded the highest $e e$ value of the entire BenzaPhos library $(88 \% e e)$, although still not comparable with the best literature precedents. ${ }^{[1]}$ In the hydrogenation of S5, ligand $\mathbf{1 s}$ allowed full conversion with virtually perfect stereocontrol, thus improving on the result obtained by using its parent ligand 1g. Together with that obtained with the PhthalaPhos ligands, ${ }^{[9]}$ this is the best result ever reported for the hydrogenation of substrate S5, for which only one highly enantioselective example had been described previously. ${ }^{[11]}$

2) No improvement was achieved by using second-generation ligands in the hydrogenation of substrates $\mathbf{S 1}$ and S3, which can be explained considering the already high level of stereocontrol obtained with the parent ligands 1b, $1 \mathrm{c}$, and $1 \mathrm{~g}$.

3) Trifluoromethyl- and methoxy-substituted ligands featuring the same linker gave very similar $e e$ values, which suggests that the electronic effects of the benzamide group are rather unimportant for stereoinduction. Therefore, the effect on the reaction of the para-substituent on the benzamide ring (compared with the unsubstituted ring) cannot be easily rationalized.

Spectroscopic studies on a precatalytic complex: A rather puzzling scenario emerged from the ${ }^{31} \mathrm{P}$ NMR analysis of the precatalytic complex formed by reaction of $\left[\mathrm{Rh}(\operatorname{cod})_{2} \mathrm{BF}_{4}\right]$ $(\operatorname{cod}=1,5$-cyclooctadiene) with a representative ligand of the BenzaPhos library (1p). When this ligand and [Rh$\left.(\operatorname{cod})_{2} \mathrm{BF}_{4}\right]$, in a 2:1 ratio, are dissolved in $\mathrm{CD}_{2} \mathrm{Cl}_{2}$ at $20^{\circ} \mathrm{C}$, two doublet signals d1 $\left(\delta=142.7 \mathrm{ppm}, J_{\mathrm{P}, \mathrm{Rh}}=189.5 \mathrm{ppm}\right)$ and d2 $\left(\delta=122.3 \mathrm{ppm}, J_{\mathrm{P}, \mathrm{Rh}}=258.7 \mathrm{ppm}\right)$ in a $44: 56$ ratio are initially visible (Figure $5 \mathrm{~A}$ ). We found that the intensity of the d1 signal slowly decreases with time, and its decrement is accelerated when the temperature is increased to $35^{\circ} \mathrm{C}$. After $10 \mathrm{~min}$ at this temperature, $\mathbf{d} \mathbf{2}$ is the only visible signal (Figure $5 \mathrm{~B}$ ) that remains. Remarkably, when the sample temper-

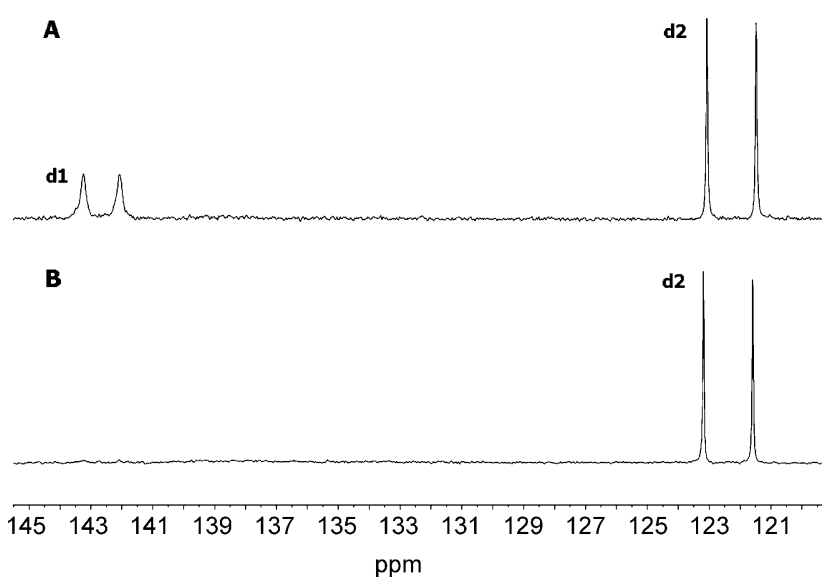

Figure 5. ${ }^{31} \mathrm{P}$ NMR spectrum of a $2: 1$ mixture of ligand 1p and [Rh$\left.(\operatorname{cod})_{2} \mathrm{BF}_{4}\right]$ after $1 \mathrm{~min}$ at $20^{\circ} \mathrm{C}(\mathrm{A})$ and after $10 \mathrm{~min}$ at $35^{\circ} \mathrm{C}(\mathrm{B})$.

ature is returned to $20^{\circ} \mathrm{C}$, the $\mathbf{d 1}$ doublet does not reappear. From this observation, we concluded that doublet d1 corresponds to a kinetic complex that is gradually converted into the thermodynamically more stable complex responsible for the d2 signal. Signal $\mathbf{d} 2$ was confidently assigned to complex $\left[\operatorname{Rh}(\mathbf{1} p)_{2}(\operatorname{cod}) \mathrm{BF}_{4}\right]$ with cis-phosphite ligands because the chemical shift and the $J_{\mathrm{P}, \mathrm{Rh}}$ value are very close to those previously reported for the precatalytic complexes of the PhthalaPhos ligands. ${ }^{[9 a]}$

High-resolution MS (ESI) analysis confirmed this assignment, showing a molecular peak at $m / z=1457.289$ that corresponds to the cationic complex $\left[\operatorname{Rh}(\mathbf{1} \mathbf{p})_{2}(\operatorname{cod})\right]^{+}$. Doublet d1 was tentatively assigned to the complex $\left[\operatorname{Rh}(\mathbf{1} \mathbf{p})_{4} \mathrm{BF}_{4}\right]$ for the following reasons: 1) the observed multiplicity is consistent with a complex featuring chemically equivalent phosphorus atoms; 2) the singlet signal of excess free ligand $\mathbf{1 p}$ is not present in the ${ }^{31} \mathrm{P}$ NMR spectrum featuring $\mathbf{d} \mathbf{1}$ and $\mathbf{d} \mathbf{2}$ (Figure 5 A), as would be expected if $\mathbf{d 1}$ belonged to the monophosphite complex $\left[\operatorname{Rh}(\mathbf{1} \mathbf{p})(\operatorname{cod}) \mathrm{BF}_{4}\right]$; and 3$)$ the d1 signal is not present in the ${ }^{31} \mathrm{P}$ NMR spectrum of mixtures with lower ligand/[Rh] ratio (1:1 and 1:2), for which only doublet d2 is detected. As additional support for our hypothesis, in the ${ }^{31} \mathrm{P}$ NMR spectrum of a $4: 1$ mixture of $\mathbf{1 p}$ and $\left[\mathrm{Rh}(\operatorname{cod})_{2} \mathrm{BF}_{4}\right]$ in $\mathrm{CD}_{2} \mathrm{Cl}_{2}$ only the $\mathbf{d 1}$ signal is present. MS (ESI) analysis of the latter mixture (in $\mathrm{CH}_{2} \mathrm{Cl}_{2}$ ) showed 
a molecular peak with $\mathrm{m} / z=2595.500$, corresponding to the cationic complex $\left[\operatorname{Rh}(\mathbf{1} \mathbf{p})_{4}\right]^{+}$.

Control experiments The superiority discussed above-in terms of catalytic activity and enantioselectivity-of the BenzaPhos ligands over the reference BINOL-phosphites 3a and $\mathbf{3 b}$ strongly suggests that their amide group affects the catalytic behavior by virtue of its hydrogen-bonding properties. The effect of hydrogen-bonding groups on the catalytic performance of monodentate $\mathrm{P}$ ligands has been interpreted previously in terms of the formation of rigid and stereodefined "supramolecular bidentate ligands" by ligandligand interactions, ${ }^{[6 \mathrm{~h}, 11,20]}$ or as a result of substrate orientation due to ligand-substrate interactions taking place in the catalytic cycle. ${ }^{[6 \mathrm{~h}, 9 \mathrm{~b}, 21]}$ Both of these approaches, which have also been applied simultaneously within the same catalytic system,${ }^{[20 s, 21 \mathrm{~b}]}$ result in an improvement of the activity and/or regio- and stereoselectivity of the ligands compared with structurally related, simple monodentate ligands. To further prove the influence of hydrogen bonding on the catalytic properties of BenzaPhos ligands, and to gain insight into its actual role, we carried out a series of control experiments, which are described in this section.

The secondary amide group in BenzaPhos ligands 1as possesses both a hydrogen-bond donor site (the amide $\mathrm{NH}$ hydrogen atom ) and a hydrogen bond acceptor group (the amide $\mathrm{CO}$ oxygen atom). For this reason, BenzaPhos ligands are, in principle, able to form both ligand-ligand and ligand-substrate hydrogen bonds. To ascertain whether the former or the latter interactions are responsible for the catalytic properties of the ligands, phosphite 1p-Me (Figure 6), an $\mathrm{N}$-methylated version of ligand $\mathbf{1 p}$, was synthesized as described in the Supporting Information.

Unlike the other members of the BenzaPhos library (1as), ligand 1p-Me is devoid of a hydrogen-bond donor group, and thus is unable to self-assemble into a "supramolecular bidentate ligand" by means of interligand hydrogen bonding. We thus screened ligand 1p-Me in the hydrogenation of challenging substrates $\mathbf{S 4}$ and $\mathbf{S 5}$, obtaining the results shown in Table 8. With substrate $\mathbf{S 4}$ (Table 8, entries 1 and 2), ligand 1p-Me gave full conversion and the same outstanding level of stereocontrol as the parent ligand 1p. In the hydrogenation of substrate $\mathbf{S 5}$ (Table 8, entries 3 and 4), 1pMe gave improved conversion and $e e$ with respect to the parent ligand $\mathbf{1}$ p.

We also carried out kinetic studies on the hydrogenation of S4, to compare the catalytic activities of ligands $\mathbf{1 p}$ and $\mathbf{1 p -}$

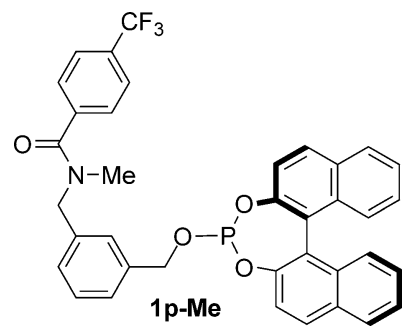

Figure 6. Phosphite 1p-Me, a $N$-methylated version of ligand $\mathbf{1 p}$.

Table 8. The use of $N$-methylated ligand 1p-Me in the enantioselective hydrogenation of $N$-(3,4-dihydronaphthalen-1-yl)acetamide $\mathbf{S 4}$ and methyl (E)-2-(acetamidomethyl)-3-phenylacrylate S5. ${ }^{[a]}$

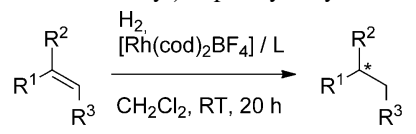

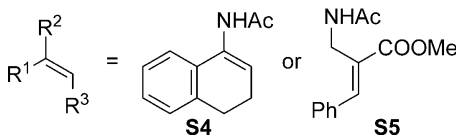

\begin{tabular}{lllcc}
\hline & Substrate & Ligand & Conv. [\%] & $\begin{array}{c}\text { ee [\%], } \\
\text { abs. conf. }\end{array}$ \\
\hline 1 & S4 & 1p & 100 & $>99, R$ \\
2 & S4 & 1p-Me & 100 & $>99, R$ \\
3 & S5 & 1p & 28 & $90, R$ \\
4 & S5 & 1p-Me & 46 & $96, R$ \\
\hline
\end{tabular}

[a] For reaction and $e e$ determination conditions for $\mathbf{S 4}$, see the footnotes of Table 4, and for $\mathbf{S 5}$, see the footnotes of Table 5 .

Me. The experiments were set up in parallel by using a Parr multireactor, and the conversion values were calculated from the hydrogen uptake. The typical pseudo-first-order kinetic profiles obtained are shown in Figure 7, together with that of the rhodium complex of reference ligand $\mathbf{3} \mathbf{b}^{[0 b]}$

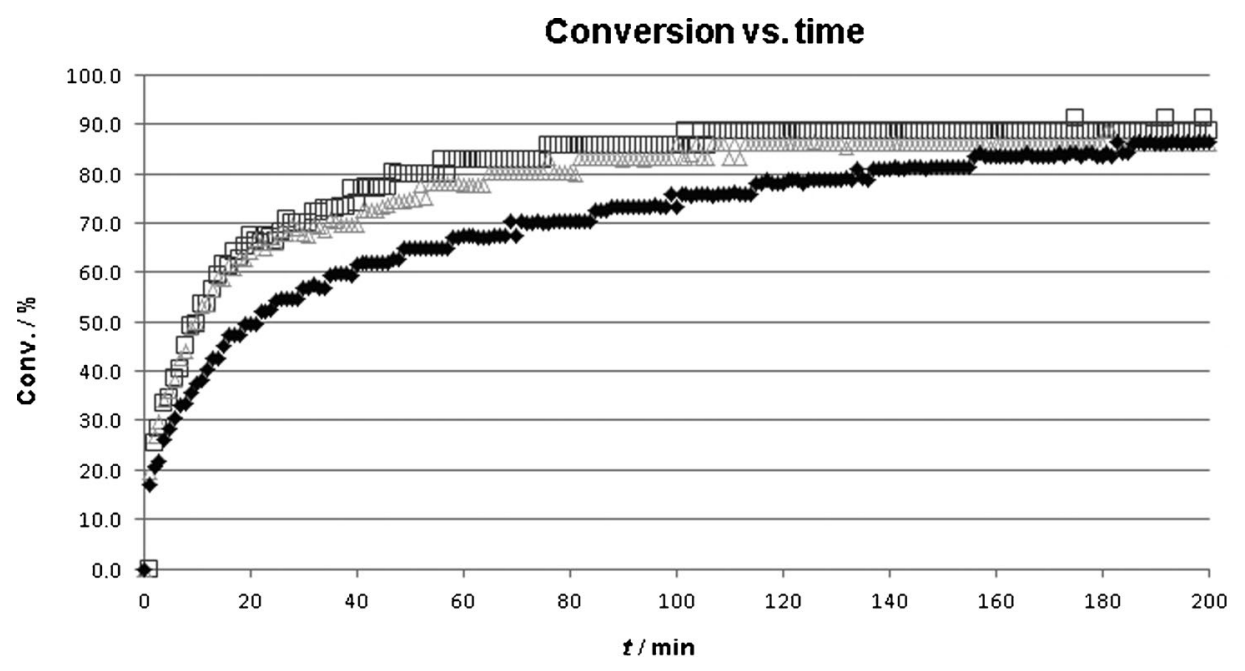

Figure 7. Kinetics of hydrogenation of substrate $\mathbf{S 4}$ catalyzed by the rhodium complex of ligand $\mathbf{1 p}(\square), \mathbf{1 p -}$ Me $(\Delta)$ and reference ligand $\mathbf{3 b}(\bullet)$, respectively. Solvent $=\mathrm{CH}_{2} \mathrm{Cl}_{2} ; c_{0}(\mathbf{S 4})=0.331 \mathrm{~m} ; P_{\text {hydrogen }}=60$ bar; $T=$ $25^{\circ} \mathrm{C}$; catalyst loading $=1 \mathrm{~mol} \% ; c$ (cat.) $=3.31 \mathrm{~mm}$. 
Table 9. Kinetic parameters of the hydrogenation of $N$-(3,4-dihydronaphthalen-1-yl)acetamide $\mathbf{S 4}$ catalyzed by the $\mathbf{1} \mathbf{p}-\mathbf{1} \mathbf{p}-\mathbf{M e}-$, and $\mathbf{3 b}$-rhodium complexes, respectively. ${ }^{[a]}$

\begin{tabular}{lllll}
\hline & $k_{\text {app }}\left[\mathrm{min}^{-1}\right]^{[\mathrm{b}]}$ & $t_{1 / 2}[\mathrm{~min}]$ & $k\left[\mathrm{~L} \mathrm{~mol}^{-1} \mathrm{~min}^{-1}\right]^{[\mathrm{b}]}$ & $\mathrm{TOF}\left[\mathrm{h}^{-1}\right]^{[\mathrm{c}]}$ \\
\hline $\mathbf{1 p}$ & 0.051 & 13.7 & 15.3 & 244 \\
$\mathbf{1 p}-\mathbf{M e}$ & 0.049 & 14.1 & 14.8 & 235 \\
$\mathbf{3 b}$ & 0.028 & 24.4 & 8.6 & 180 \\
\hline
\end{tabular}

[a] Solvent $=\mathrm{CH}_{2} \mathrm{Cl}_{2} ; \quad c_{0}(\mathbf{S 4})=0.331 \mathrm{M} ; P_{\text {hydrogen }}=60$ bar; catalyst loading $=1 \mathrm{~mol} \% ; c$ (cat.) $=3.31 \mathrm{~mm}$. [b] $k_{\text {app }}=k \times c$ (cat.). [c] Determined at $t=15 \mathrm{~min}$.

These kinetic profiles and the calculated parameters (firstorder $k_{\text {app }}$, second-order $k$, half-life $t_{1 / 2}$, and turnover frequency (TOF)) given in Table 9, show that the complexes of 1p and 1p-Me have very similar catalytic activities, which are significantly higher than that of the complex of reference ligand $\mathbf{3 b}$ (devoid of the amide group).

The results of the control experiments described above suggest that the amide $\mathrm{NH}$ group in ligands $\mathbf{1 a}-\mathbf{s}$ is not involved in hydrogen-bonding interactions relevant for the catalytic properties. Hydrogen bonds between ligands coordinated to rhodium - although possibly present for ligands $\mathbf{1 a}-\mathbf{s}$ in the precatalyst or at some stage of the catalytic cycle-are not responsible for the outstanding catalytic properties of BenzaPhos ligands. Hydrogen bonding is therefore likely to occur between the amide oxygen of the ligand and a hydrogen-bond donor group of the substrate, and results in a substrate-orientating effect during the catalytic cycle.

To further prove the influence of hydrogen bonding on the catalytic properties of BenzaPhos ligands, we decided to perform the hydrogenation of $\mathbf{S 4}$ and $\mathbf{S 5}$ in a solvent more polar than $\mathrm{CH}_{2} \mathrm{Cl}_{2}$ because solvent polarity is expected to disrupt ligand-substrate hydrogen bonds, and thus to erode both catalytic activity and enantioselectivity. However, it is known that polar and protic solvents lead to a dramatic drop in enantioselectivity in the hydrogenations catalyzed by rhodium complexes of monophosphite ligands, ${ }^{[0 \mathrm{~b}, 22]}$ and thus experiments run in solvents such as AcOEt, THF, or $i \mathrm{PrOH}$ would not provide any useful information on the role of hydrogen bonding.

For this reason, we decided to perform the experiments in $\mathrm{CF}_{3} \mathrm{CH}_{2} \mathrm{OH}$, a protic solvent that we have found not to significantly erode the catalytic performance of simple BINOL-based monophosphites, such as $\mathbf{3 a}$ and $\mathbf{3 b}{ }^{[0 b]}$ For each substrate, we screened reference phosphite $\mathbf{3 b}$, the best-performing ligand of the library (1p for S4 and 1s for S5), and the $N$-methylated ligand 1p-Me, obtaining the results given in Table 10. Although fluorinated alcohols, which are highly polar solvents but poor hydrogen-bond acceptors, were reported not to disturb the hydrogen bonds of selfassembled rhodium-phosphine complexes, ${ }^{[23]}$ we observed a substantial drop in conversion and ee value when the hydrogenations promoted by BenzaPhos-rhodium complexes were carried out in 7:1 $\mathrm{CF}_{3} \mathrm{CH}_{2} \mathrm{OH} / \mathrm{CH}_{2} \mathrm{Cl}_{2}$ (Table 10, entries 4 vs. 3,6 vs. 5,10 vs. 9 , and 12 vs. 11). On the other hand, the rhodium complex of reference monophosphite $\mathbf{3 b}$
Table 10. Solvent screening in the hydrogenation of substrates $\mathbf{S 4}$ and $\mathbf{S 5}$ with ligands $\mathbf{1} \mathbf{p}, \mathbf{1}$ s, $\mathbf{1} \mathbf{p}-\mathbf{M e}$, and $\mathbf{3 b}$. $^{[\mathrm{a}]}$

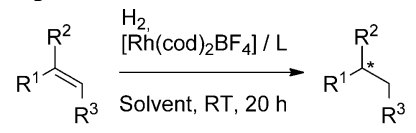

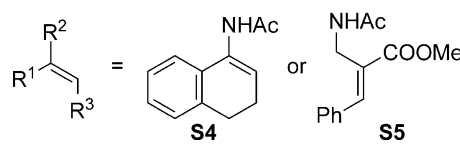

\begin{tabular}{|c|c|c|c|c|c|}
\hline & Substrate & Ligand & Solvent & $\begin{array}{l}\text { Conv. } \\
{[\%]}\end{array}$ & $\begin{array}{l}e e[\%], \\
\text { abs. conf. }\end{array}$ \\
\hline 1 & S4 & $\mathbf{3 b}$ & $\mathrm{CH}_{2} \mathrm{Cl}_{2}$ & 100 & $96, R$ \\
\hline 2 & S4 & $3 \mathbf{b}$ & $\mathrm{CF}_{3} \mathrm{CH}_{2} \mathrm{OH} / \mathrm{CH}_{2} \mathrm{Cl}_{2}(7: 1)$ & 100 & $93, R$ \\
\hline 3 & S4 & $1 \mathbf{p}$ & $\mathrm{CH}_{2} \mathrm{Cl}_{2}$ & 100 & $>99, R$ \\
\hline 4 & S4 & $1 \mathbf{p}$ & $\mathrm{CF}_{3} \mathrm{CH}_{2} \mathrm{OH} / \mathrm{CH}_{2} \mathrm{Cl}_{2}(7: 1)$ & 44 & $38, R$ \\
\hline 5 & S4 & 1 p-Me & $\mathrm{CH}_{2} \mathrm{Cl}_{2}$ & 100 & $>99, R$ \\
\hline 6 & S4 & $1 \mathrm{p}-\mathrm{Me}$ & $\mathrm{CF}_{3} \mathrm{CH}_{2} \mathrm{OH} / \mathrm{CH}_{2} \mathrm{Cl}_{2}(7: 1)$ & 78 & $61, R$ \\
\hline 7 & S5 & $\mathbf{3 b}$ & $\mathrm{CH}_{2} \mathrm{Cl}_{2}$ & 37 & $90, R$ \\
\hline 8 & S5 & $\mathbf{3 b}$ & $\mathrm{CF}_{3} \mathrm{CH}_{2} \mathrm{OH} / \mathrm{CH}_{2} \mathrm{Cl}_{2}(7: 1)$ & 45 & $93, R$ \\
\hline 9 & S5 & $1 \mathrm{~s}$ & $\mathrm{CH}_{2} \mathrm{Cl}_{2}$ & 100 & $>99, R$ \\
\hline 10 & S5 & $1 \mathrm{~s}$ & $\mathrm{CF}_{3} \mathrm{CH}_{2} \mathrm{OH} / \mathrm{CH}_{2} \mathrm{Cl}_{2}(7: 1)$ & 57 & $89, R$ \\
\hline 11 & S5 & $1 \mathrm{p}-\mathrm{Me}$ & $\mathrm{CH}_{2} \mathrm{Cl}_{2}$ & 46 & $96, R$ \\
\hline 12 & S5 & 1 p-Me & $\mathrm{CF}_{3} \mathrm{CH}_{2} \mathrm{OH} / \mathrm{CH}_{2} \mathrm{Cl}_{2}(7: 1)$ & 44 & $64, R$ \\
\hline
\end{tabular}

[a] For reaction and $e e$ determination conditions for $\mathbf{S 4}$, see the footnotes of Table 4, and for S5, see the footnotes of Table 5 .

maintained essentially the same level of conversion and stereoselectivity when switching from $\mathrm{CH}_{2} \mathrm{Cl}_{2}$ to $7: 1$ $\mathrm{CF}_{3} \mathrm{CH}_{2} \mathrm{OH} / \mathrm{CH}_{2} \mathrm{Cl}_{2}$ (Table 10, entries 2 vs. 1 and 8 vs. 7). Therefore, this experiment confirms that hydrogen-bonding interactions play an important role in determining the catalytic behavior of the BenzaPhos ligands.

With the aim of further investigating the role of hydrogen bonding between the BenzaPhos ligand amide oxygen atom and the substrate hydrogen-bond donor group during the catalytic cycle, we performed the hydrogenation of substrates structurally related to $\mathbf{S 4}$ and $\mathbf{S 5}$, but lacking the amide NH hydrogen atom: the $N$-methyl analogues S4-Me and S5-Me, and the esters S4-O and S5-O (Figure 8). ${ }^{[24]} \mathrm{Al}-$ though the modifications introduced in the substrates probably affect their stereoelectronic properties well beyond the simple loss of hydrogen-bond donor ability, we believe that these experiments may usefully support or contradict our hypotheses on the ligand-substrate interactions. For each series of analogues (Table 11 and Table 12, respectively) the rhodium complexes of $\mathbf{1} \mathbf{p}-\mathbf{M e}$ and of the BenzaPhos ligand
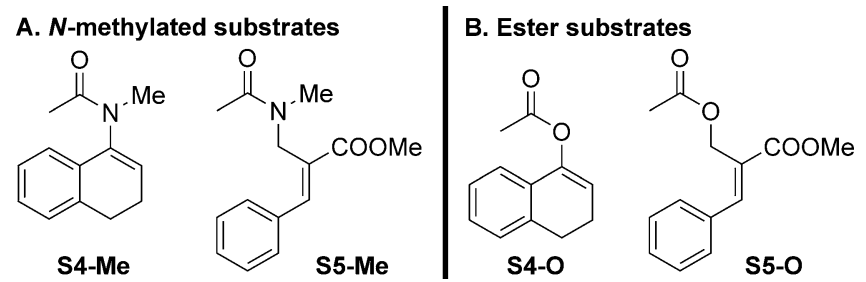

Figure 8. A) $N$-methylated substrates S4-Me and S5-Me. B) ester substrates S4-O and S5-O. 
Table 11. Hydrogenation of substrate $\mathbf{S 4}$ and its analogues (S4-Me and S4-0) by using ligands $\mathbf{1 p}$ and $\mathbf{1 p - M e} .^{[a]}$

\begin{tabular}{|c|c|c|c|c|c|}
\hline & \multicolumn{2}{|c|}{$\begin{array}{l}\text { S4: } X=N H \\
\text { S4-Me: } X=N M e \\
\text { S4-O: } X=O\end{array}$} & \multicolumn{3}{|c|}{$\begin{array}{l}\text { P4: } X=N H \\
\text { P4-Me: } X=N M e \\
\text { P4-O: } X=O\end{array}$} \\
\hline & Substrate & Ligand & $\begin{array}{l}P \\
{[\text { bar }]}\end{array}$ & $\begin{array}{l}\text { Conv. } \\
{[\%]}\end{array}$ & $\begin{array}{l}e e[\%], \\
\text { abs. conf. or }[\alpha]_{\mathrm{D}} \text { sign }\end{array}$ \\
\hline & $\mathbf{S} \mathbf{4}^{[\mathrm{b}]}$ & $1 p$ & 20 & 100 & $>99, R$ \\
\hline & $\mathbf{S}^{\left[{ }^{b]}\right.}$ & $1 \mathrm{p}-\mathrm{Me}$ & 20 & 100 & $>99, R$ \\
\hline & $\mathbf{S 4}-\mathbf{M e}^{[\mathrm{c}]}$ & $1 p$ & 20 & 2 & $68,(+)$ \\
\hline & S4-Me ${ }^{[c]}$ & $1 \mathrm{p}-\mathrm{Me}$ & 20 & 13 & $87,(+)$ \\
\hline & S4-O ${ }^{[\mathrm{d}]}$ & $1 p$ & 110 & 11 & $17, R$ \\
\hline & S4-O ${ }^{[\mathrm{d}]}$ & $1 \mathrm{p}-\mathrm{Me}$ & 110 & 33 & $49, R$ \\
\hline
\end{tabular}

[a] Reaction conditions: substrate/ligand/[Rh( $\left.\operatorname{cod})_{2} \mathrm{BF}_{4}\right]=100: 2.2: 1$, solvent $=\mathrm{CH}_{2} \mathrm{Cl}_{2}, c_{0}$ (substrate) $=0.024 \mathrm{M}, T=25^{\circ} \mathrm{C}$. [b] Conversion and $e e$ determined as specified in the footnotes of Table 4. [c] Conversion and $e e$ determined by GC with a chiral capillary column (MEGADEX DACTBS $\beta$, diacetyl-tert-butylsilyl- $\beta$-cyclodextrin); correlation of $[\alpha]_{\mathrm{D}}$ sign with the absolute configuration still not established. [d] Conversion determined by ${ }^{1} \mathrm{H}$ NMR spectroscopy on the crude reaction mixture; $e e$ determined by HPLC with a chiral column (Phenomenex Lux Cellulose 3 ); absolute configuration assigned by comparison of the sign of the optical rotation with literature data. ${ }^{[25]}$

that performs best with the parent olefin (1p for $\mathbf{S 4}$ and $1 \mathrm{~s}$ for S5) were employed.

As shown in Table 11, the hydrogenation of S4-Me gave poor conversions and significantly depleted ee values (compared with those obtained with the parent substrate S4), with both $\mathbf{1 p}$ (Table 11, entry 3 vs. 1) and 1p-Me (Table 11, entry 4 vs. 2) as the chiral ligand. The enol ester S4-O displayed very poor reactivity in the presence of ligands $\mathbf{1 p}$ and $\mathbf{1}$-Me, and forcing conditions (110 bar hydrogen pressure) were required to achieve meaningful conversions. Low $e e$ values (absolute configuration of the product assigned by comparison of the sign of the optical rotation with literature data $^{[25]}$ ) were obtained with both ligand $\mathbf{1 p}$ and $\mathbf{1 p - M e}$ (Table 11, entries 5 and 6). Although other stereoelectronic factors may contribute to the observed outcome, these results can also be justified by the lack of an amide NH hydrogen-bond donor in the substrate, which prevents the interaction with the carbonyl oxygen in the BenzaPhos ligand from occurring.

In addition, the results obtained for the hydrogenation of the $\mathbf{S 5}$ analogues (Table 12) are consistent with our interpretation of the catalytic behavior of the BenzaPhos ligands: both ligands $1 \mathrm{~s}$ and $\mathbf{1 p}$-Me proved remarkably less active and slightly less enantioselective with substrate S5-Me than with the parent compound S5 (Table 12, entries 4 vs. 1 and 5 vs. 2). The drop in enantioselectivity is relatively small because the hydrogenation of S5-Me occurs with rather high $e e$ independent of the ligand employed: even the reference phosphite 3a, unable to form hydrogen bonds and performing poorly with the parent substrate S5 (Table 12, entry 3 ), afforded a respectable $91 \%$ ee (Table 12 , entry 6 ). The hy-
Table 12. Hydrogenation of substrate $\mathbf{S 5}$ and its analogues (S5-Me and 55-0) by using ligands $\mathbf{1 s}$ and $\mathbf{1} \mathbf{p}-\mathbf{M e} .^{[a]}$

\begin{tabular}{|c|c|c|c|c|}
\hline $\begin{array}{l}\mathrm{COC} \\
\mathrm{s} 5: \\
\mathrm{S} 5- \\
\mathrm{s} 5-\end{array}$ & $\begin{array}{l}\mathrm{NH} \\
X=\mathrm{NMe} \\
=\mathrm{O}\end{array}$ & $\mathrm{CH}_{2} \mathrm{Cl}_{2}, \mathrm{R}$ & $20 \mathrm{~h}$ & $\begin{array}{l}\text { COOMe } \\
\text { P5: } X=N H \\
\text { P5-Me: } X=N M e \\
\text { P5-O: } X=O\end{array}$ \\
\hline Substrate & Ligand & $\begin{array}{l}P \\
{[\text { bar }]}\end{array}$ & $\begin{array}{l}\text { Conv. } \\
{[\%]}\end{array}$ & $\begin{array}{l}e e[\%], \\
\text { abs. conf. or }[\alpha]_{D} \text { sign }\end{array}$ \\
\hline $\mathbf{S 5}^{[\mathrm{b}]}$ & $1 \mathrm{~s}$ & 50 & 100 & $>99, R$ \\
\hline $\mathbf{S} 5^{[b]}$ & 1p-Me & 50 & 46 & $96, R$ \\
\hline $\mathbf{S 5}^{5^{[b]}}$ & 3a & 50 & 6 & $32, R$ \\
\hline S5-Me $\mathbf{M e}^{[c]}$ & $1 \mathrm{~s}$ & 50 & 15 & $91,(+)$ \\
\hline $\mathbf{S 5}-\mathbf{M e}^{[\mathrm{cc}]}$ & $1 \mathrm{p}-\mathrm{Me}$ & 50 & 28 & $92,(+)$ \\
\hline $\mathbf{S 5}-\mathbf{M e}^{[\mathrm{c}]}$ & $3 \mathbf{a}$ & 50 & 4 & $91,(+)$ \\
\hline S5-O $\mathbf{O}^{[\mathrm{d}]}$ & $1 \mathrm{~s}$ & 110 & 0 & - \\
\hline S5-O-O $\mathbf{O}^{[\mathrm{d}]}$ & $1 \mathrm{p}-\mathrm{Me}$ & 110 & 0 & - \\
\hline
\end{tabular}

[a] Reaction conditions: substrate/ligand/[Rh( $\left.\operatorname{cod})_{2} \mathrm{BF}_{4}\right]=100: 2.2: 1$, solvent $=\mathrm{CH}_{2} \mathrm{Cl}_{2}, c_{0}$ (substrate) $=0.024 \mathrm{M}, T=25^{\circ} \mathrm{C}$. [b] Conversion and $e e$ determined as specified in the footnotes of Table 5. [c] Conversion determined by ${ }^{1} \mathrm{H}$ NMR spectroscopy on the crude reaction mixture; ee determined by HPLC with a chiral column (Phenomenex Lux Cellulose 2) [d] Conversion determined by ${ }^{1} \mathrm{H}$ NMR spectroscopy on the crude reaction mixture; ee determined by HPLC with a chiral column (Daicel Chiralcel OD-H).

drogenation of substrate S5-O did not lead to any product even under forcing conditions (Table 12, entries 7 and 8).

On the whole, the control experiments demonstrate that hydrogen-bonding interactions significantly affect the catalytic behavior of BenzaPhos ligands, allowing them to access higher conversion and $e e$ values than the related BINOLmonophosphites devoid of amide groups. Moreover, the experimental results strongly suggest that the hydrogen bond responsible for the outstanding performances of the ligands should form - in the hydrogenation catalytic cycle-between the ligand amide carbonyl oxygen atom and the substrate hydrogen-bond donor group.

Computational studies: As a complement to the experimental evidence derived from the aforementioned experiments, we set out to develop a computational model of a hydrogenation intermediate for which the ligand-substrate hydrogen bond could be visualized. Since this hydrogen bond is influential on the stereocontrol, we decided to focus on an intermediate in the catalytic cycle located as close as possible to the stereodiscriminating step of the process. According to most of the literature concerning the mechanism of rhodium-catalyzed asymmetric hydrogenation, ${ }^{[26]}$ stereoselection takes place during the formation of chelate octahedral dihydride rhodium complexes. In particular, recent studies carried out by Gridnev, Imamoto and co-workers ${ }^{[26 \mathrm{~h}-\mathrm{i}]}$ describe the hydrogenation process as a sequence of reversible steps, the stereoselectivity of which is determined at the reversible stage of association of the double bond in the rapidly interconverting dihydrides $\mathbf{A}$ and $\mathbf{A}^{\prime}$ to give the chelate dihydrides $\mathbf{B}$ and $\mathbf{B}^{\prime}$ (Scheme 4).

Consequently, the stereochemical outcome should depend on which enantioface of the substrate is coordinated to rho- 


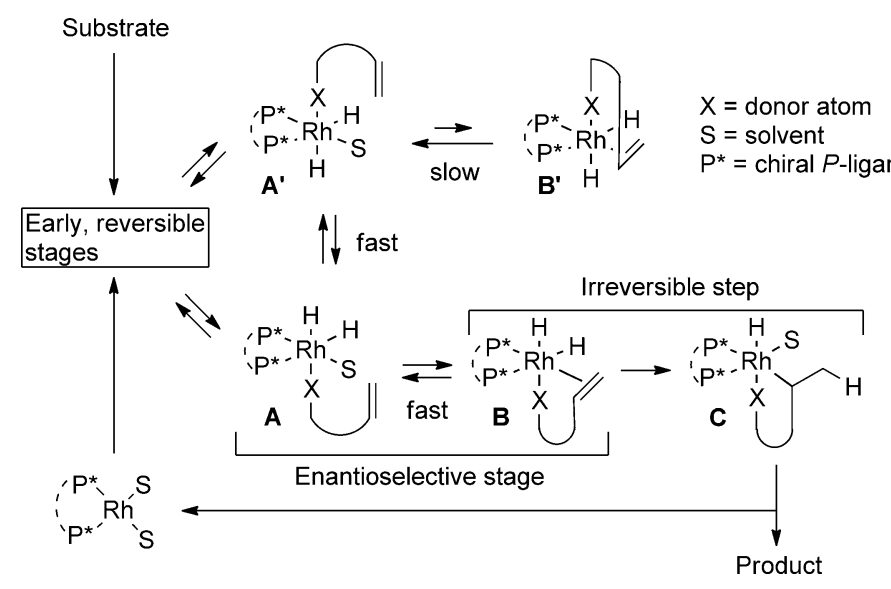

Scheme 4 . The stereodiscriminating step of the rhodium-catalyzed hydrogenation according to recent literature contributions. ${ }^{[26 \mathrm{~h}-1]}$

dium in the chelate dihydride with the lowest activation energy of formation (B in Scheme 4). The subsequent migratory-insertion step, a fast and irreversible step, fixes the result of the enantioselection, forming the monohydride $\mathbf{C}$, which is then converted into the product. Although this mechanistic interpretation was initially developed for hydrogenations promoted by rhodium complexes of chiral diphosphines, a recent study has demonstrated its validity in the presence of chiral monophosphine-rhodium catalysts. ${ }^{[27]} \mathrm{Re}-$ markably, in the latter, migratory insertion should be included among the reversible steps, and only the final reductive elimination $(\mathbf{C} \rightarrow$ catalyst + reaction product $)$ would be irreversible.

On the basis of this mechanistic interpretation, we decided to build computational models of B-type dihydride intermediates for the hydrogenation of substrate $\mathbf{S 4}$ promoted by the rhodium complex of ligand $\mathbf{1} \mathbf{p}$, with the expectation of finding structures featuring the ligand-substrate hydrogen bond suggested by the experimental data. Among the eight possible dihydride complexes, ${ }^{[26 \mathrm{~d}, \mathrm{~h}]}$ we considered only those satisfying the following criteria: 1) a cis disposition of the phosphite ligands around rhodium, as suggested by the literature for the catalytic rhodium complexes of monodentate $\mathrm{P}$ ligands, ${ }^{[27,28]}$ and by the aforementioned structure of the precatalytic complex $\left.\left[\operatorname{Rh}(\mathbf{1} \mathbf{p})_{2}(\operatorname{cod}) \mathrm{BF}_{4}\right] ; 2\right)$ a cis disposition of hydride $\mathrm{H}$ atoms, as a consequence of oxidative addition to rhodium $;{ }^{[26]}$ and 3 ) the coordination of the carbonyl oxygen

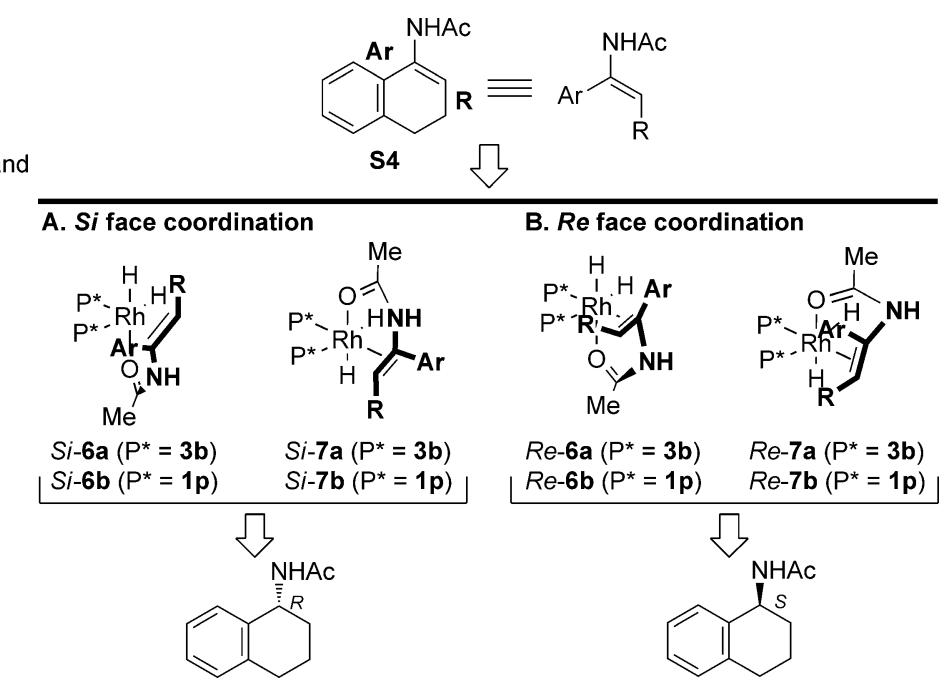

Figure 9. A) Pro- $R$ chelate dihydride complexes ( $S i$ face of the substrate coordinated to $\mathrm{Rh}$ ). B) Pro- $S$ chelate dihydride complexes ( $R e$ face of the substrate coordinated to $\mathrm{Rh}$ ).

trans to a hydride $\mathrm{H}$ atom, as suggested by experimental evidence reported in the literature. ${ }^{[26, i]}$

We thus focused our attention on the four dihydrides shown in Figure 9, two of which (Si-6b and Si-7b) are precursors of the experimentally determined major enantiomer of the product $(R,>99 \% e e)$, whereas the others $(R e-6 \mathbf{b}$ and $R e-7 \mathbf{b})$ lead to the minor enantiomer. Computational models of dihydrides $S i-6 \mathbf{b}, S i-7 \mathbf{b}, R e-6 \mathbf{b}$, and $R e-7 \mathbf{b}$ were built by implementing the following workflow: $\left.{ }^{[29]} 1\right)$ a preliminary DFT optimization (B3LYP/LACVP level of theory $)^{[30]}$ was carried out on dihydrides $\mathrm{Si}-\mathbf{6 a}, \mathrm{Si}-\mathbf{7} \mathbf{a}, \mathrm{Re}-\mathbf{6} \mathbf{a}$, and $R e-7 \mathbf{a}$ (containing monodentate phosphite $\mathbf{3 b}$ as ligand $\mathrm{P}^{*}$, see Figure 9);2) the amide group was introduced on the ligands $\left(\mathrm{P}^{*}=\mathbf{1} \mathbf{p}\right)$, and Monte Carlo/energy minimization conformational searches ${ }^{[1,32]}$ were performed (AMBER*, $\left.\mathrm{CHCl}_{3} \mathrm{~GB} / \mathrm{SA}\right)^{[33]}$ keeping the geometries of the preoptimized octahedral core (Si-6a, Si-7a, Re-6a, and $R e-7 \mathbf{a})$ frozen and leaving the amide groups free to move; and finally, 3) the $S i-\mathbf{6 b}, S i-7 \mathbf{b}, R e-6 \mathbf{b}$, and $R e-7 \mathbf{b}$ global-minimum geometries of $\mathrm{MC} / \mathrm{EM}$ searches were optimized at the DFT B3LYP/LACVP level of theory. ${ }^{[30]}$

The structures of the dihydride complexes and their relative energies, resulting from these computational studies, are
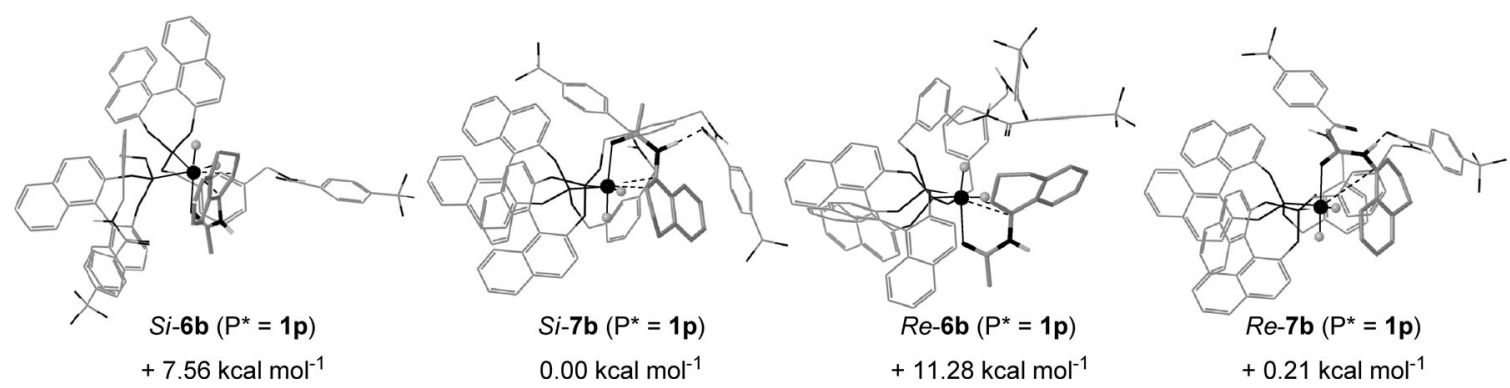

Figure 10. DFT-optimized structures of dihydrides $S i-6 \mathbf{b}, S i-7 \mathbf{b}, R e-6 \mathbf{b}$, and $R e-7 \mathbf{b}$ with relative energies in $\mathrm{kcal} \mathrm{mol}^{-1}[\mathrm{wires}(\mathrm{P}$ ligands) and tubes (substrate S4): grey $=\mathrm{C}$, light grey $=$ amide $\mathrm{H}$ atoms, black $=$ heteroatoms $(\mathrm{N}, \mathrm{O}, \mathrm{P})$; CPK spheres: black $=\mathrm{Rh}$, grey $=\mathrm{H}$. For the sake of clarity, all $\mathrm{H}$ atoms bound to carbon are omitted]. 
displayed in Figure 10; in two of the structures ( $\mathrm{Si-7} \mathbf{b}$ and $R e-7 \mathbf{b})$, the expected hydrogen bond between the ligand's amide oxygen and the substrate's $\mathrm{NH}$ is present, whereas the others (Si-6b and $R e-6 \mathbf{b})$ do not contain any hydrogen bonds. The hydrogen-bonded structures $S i-7 \mathbf{b}$ and $R e-\mathbf{7 b}$ are far more stable than the others; dihydrides $S i-6 \mathbf{b}$ and $R e-6 \mathbf{b}$ lie 7.56 and $11.28 \mathrm{kcalmol}^{-1}$, respectively, above the minimum energy structure Si-7b. Remarkably, the observed order of stability is in qualitative agreement with the experimental stereochemical preference of the rhodium complex

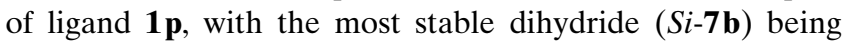
the precursor for the major enantiomer of the product $(R$, as shown in Figure 9). Moreover, it must be noted that the narrow energy gap between the hydrogen-bonded dihydrides $S i-7 \mathbf{b}$ and $R e-7 \mathbf{b}$-inconsistent with the very high experimental $e e$ value ( $>99 \%$ ) — cannot be used for a quantitative energy comparison because these intermediates were not identified as the transition states of the stereodiscriminating step. However, the results of the computational studies are in perfect agreement with the experimental information we could gather in the preceding section; the hydrogenbonding interaction responsible for the outstanding catalytic properties of this new class of chiral ligands seems to take place between the BenzaPhos amide oxygen and the substrate hydrogen-bond donor group.

\section{Conclusion}

Our results effectively show the method by which the intrinsic advantages of supramolecular transition-metal catalysis (i.e., high selectivity achieved by employing ligands capable of noncovalent interactions in addition to catalytic metal coordination $)^{[6 \mathrm{~h}]}$ can be accessed with catalysts amenable to automation for both high-throughput ligand synthesis and catalytic screening. Indeed, on the one hand the BenzaPhos ligands are of simple modular nature and very easy to prepare (only two steps from commercially or readily available staring materials), which allowed rapid optimization of the ligands' catalytic properties by simply varying one structural element (the benzamide group) of the most promising representatives of the first-generation library. On the other hand, the BenzaPhos ligands possess a functional group capable of a substrate-orientating effect during the catalytic cycle of rhodium-catalyzed hydrogenation, which allows access to outstanding levels of stereocontrol [the best ever reported $e e$ values (>99\%) have been obtained for the hydrogenation of two industrially relevant substrates, $\mathbf{S 4}$ and S5]. Control experiments and computational studies strongly suggest that such substrate orientation takes place in the catalytic cycle by formation of a hydrogen bond between the ligands' amide oxygen atom and the substrate's amide hydrogen atom.

\section{Experimental Section}

General procedure for the synthesis of BenzaPhos ligands 1a-s and 1pMe: $(S)$-BINOL-PCl (1.05 equiv) was added to a stirred solution $(0.1 \mathrm{M})$ of the selected alcohol (1 equiv, typical scale $0.2 \mathrm{~g}$ ) and $\mathrm{Et}_{3} \mathrm{~N}$ (2.5 equiv) in THF. The mixture was stirred overnight and then filtered through a pad of Celite (washing with $\mathrm{Et}_{2} \mathrm{O}$ ). The solvent was evaporated under reduced pressure and the crude product was purified by flash column chromatography over silica gel. In some cases, ${ }^{1} \mathrm{H}$ NMR analysis of the collected fraction revealed the presence of some BINOL (derived from partial degradation of the ligand during the column), which could be removed with an alkaline workup: the collected fraction was dissolved in AcOEt or $\mathrm{Et}_{2} \mathrm{O}(40 \mathrm{~mL})$ and rapidly washed three times with aqueous $\mathrm{NaOH}(1 \mathrm{M})$ and twice with water. The organic phase was dried over anhydrous $\mathrm{Na}_{2} \mathrm{SO}_{4}$, and the solvent was removed in vacuo to give the desired product (for full details and characterization, see the Supporting Information).

General procedure for asymmetric hydrogenations under atmospheric pressure: Seven oven-dried glass test tubes with stirring bars were employed: in each, the ligand ( $0.0042 \mathrm{mmol}, 0.022$ equiv) was added, then the test tubes were placed in a Schlenk flask and subjected to three vacuum/nitrogen cycles. A solution $(2.12 \mathrm{~mm})$ of $\left[\mathrm{Rh}(\operatorname{cod})_{2} \mathrm{BF}_{4}\right](0.9 \mathrm{~mL}$, $0.001909 \mathrm{mmol}, 0.01$ equiv) in $\mathrm{CH}_{2} \mathrm{Cl}_{2}$ was added and the mixtures were stirred for $10 \mathrm{~min}$ under nitrogen. A solution $(0.1909 \mathrm{M})$ of the substrate ( $1 \mathrm{~mL}, 0.1909 \mathrm{mmol}, 1$ equiv) in $\mathrm{CH}_{2} \mathrm{Cl}_{2}$ was added, followed by more $\mathrm{CH}_{2} \mathrm{Cl}_{2}(2.1 \mathrm{~mL})$. The reaction mixtures were subjected to three vacuum/ hydrogen cycles and then left stirring overnight at room temperature under 1 bar of hydrogen. Samples were taken and analyzed for conversion and ee determination (see the Supporting Information).

General procedure for asymmetric hydrogenations under pressures higher than atmospheric: A Parr multireactor was employed, allowing six reactions in parallel under hydrogen pressure. The selected ligands ( $0.0042 \mathrm{mmol}, 0.022$ equiv) were weighed into special glass vessels. The vessels were purged with nitrogen and a solution $(2.12 \mathrm{~mm})$ of [Rh(cod) $\left.{ }_{2} \mathrm{BF}_{4}\right]\left(0.9 \mathrm{~mL}, 0.001909 \mathrm{mmol}, 0.01\right.$ equiv) in $\mathrm{CH}_{2} \mathrm{Cl}_{2}$ was added to each vessel. After $10 \mathrm{~min}$, a solution $(0.1909 \mathrm{M})$ of the substrate $(1 \mathrm{~mL}$, $0.1909 \mathrm{mmol}, 1$ equiv) in $\mathrm{CH}_{2} \mathrm{Cl}_{2}$ was added, followed by more $\mathrm{CH}_{2} \mathrm{Cl}_{2}$ $(6.1 \mathrm{~mL})$, and the vessels were placed in the respective autoclaves and purged three times with hydrogen at the selected pressure. The reactions were stirred overnight at RT under the required pressure of hydrogen, and then analyzed for conversion and ee determination (see the Supporting Information).

\section{Acknowledgements}

We thank the European Commission [RTN Network (R)Evolutionary Catalysis MRTN-CT-2006-035866] for financial support. L. Pignataro thanks Milan University for a postdoctoral fellowship (Assegno di ricerca). M. Civera thanks MIUR (FIRB Futuro in Ricerca RBFR088ITV) for a postdoctoral fellowship and financial support. C. Bovio thanks Nerviano Medical Sciences for a postgraduate fellowship.

[1] For a comprehensive review, see: Catalytic Asymmetric Synthesis, 3rd ed. (Ed.: I. Ojima), Wiley, New York, 2010.

[2] J. M. Hawkins, T. J. N. Watson, Angew. Chem. 2004, 116, 3286-3290; Angew. Chem. Int. Ed. 2004, 43, 3224-3228, and references therein.

[3] a) C. Gennari, U. Piarulli, Chem. Rev. 2003, 103, 3071-3100; b) C. Jäkel, R. Paciello, Chem. Rev. 2006, 106, 2912-2942.

[4] a) A. H. M. de Vries, A. Meetsma, B. L. Feringa, Angew. Chem. 1996, 108, 2526-2528; Angew. Chem. Int. Ed. Engl. 1996, 35, 23742376; b) B. L. Feringa, M. Pineschi, L. A. Arnold, R. Imbos, A. H. M. de Vries, Angew. Chem. 1997, 109, 2733-2736; Angew. Chem. Int. Ed. Engl. 1997, 36, 2620-2623; c) E. Keller, J. Maurer, R. Naasz, T. Schrader, A. Meetsma, B. L. Feringa, Tetrahedron: 
Asymmetry 1998, 9, 2409-2413; d) F. Guillen, J.-C. Fiaud, Tetrahedron Lett. 1999, 40, 2939-2942; e) A. Gillon, K. Heslop, D. J. Hyett, A. Martorell, A. G. Orpen, P. G. Pringle, C. Claver, E. Fernandez, Chem. Commun. 2000, 961-962; f) M. T. Reetz, T. Sell, Tetrahedron Lett. 2000, 41, 6333-6336; g) M. T. Reetz, G. Mehler, Angew. Chem. 2000, 112, 4047-4049; Angew. Chem. Int. Ed. 2000, 39, 3889-3890; h) M. van den Berg, A. J. Minnaard, E. P. Schudde, J. van Esch, A. H. M. de Vries, J. G. de Vries, B. L. Feringa, J. Am. Chem. Soc. 2000, 122, 11539-11540; i) B. L. Feringa, Acc. Chem. Res. 2000, 33, 346-353, and references therein; j) A. Alexakis, C. Benhaim, Eur. J. Org. Chem. 2002, 3221-3236, and references therein.

[5] For a review on this approach, see: M. T. Reetz, Angew. Chem. 2008, 120, 2592-2626; Angew. Chem. Int. Ed. 2008, 47, 2556-2588.

[6] For relevant reviews, see: a) B. Breit, Angew. Chem. 2005, 117, 6976-6986; Angew. Chem. Int. Ed. 2005, 44, 6816-6825; b) M. J. Wilkinson, P. W. N. M. van Leeuwen, J. N. H. Reek, Org. Biomol. Chem. 2005, 3, 2371-2383; c) A. J. Sandee, J. N. H. Reek, Dalton Trans. 2006, 3385-3391; d) P. W. N. M. van Leeuwen, Supramolecular Catalysis, Wiley-VCH, Weinheim, 2008; e) P. E. Goudriaan, P. W. N. M. van Leeuwen, M.-N. Birkholz, J. N. H. Reek, Eur. J. Inorg. Chem. 2008, 2939-2958; f) G. Gasparini, M. Dal Molin, L. J. Prins, Eur. J. Org. Chem. 2010, 2429-2440; g) J. Meeuwissen, J. N. H. Reek, Nat. Chem. 2010, 2, 615-621; h) S. Carboni, C. Gennari, L. Pignataro, U. Piarulli, Dalton Trans. 2011, 40, 4355-4373.

[7] a) C. Monti, C. Gennari, U. Piarulli, J. G. de Vries, A. H. M. de Vries, L. Lefort, Chem. Eur. J. 2005, 11, 6701-6717; b) C. Monti, C. Gennari, U. Piarulli, Chem. Commun. 2005, 5281-5283; c) C. Marelli, C. Monti, C. Gennari, U. Piarulli, Synlett 2007, 2213-2216; d) C. Monti, C. Gennari, U. Piarulli, Chem. Eur. J. 2007, 13, 1547-1558; e) S. Carboni, L. Pignataro, C. Gennari, U. Piarulli, Tetrahedron: Asymmetry 2009, 20, 1185-1190; f) L. Pignataro, B. Lynikaite, R. Colombo, S. Carboni, M. Krupička, U. Piarulli, C. Gennari, Chem. Commun. 2009, 3539-3541.

[8] a) B. Lynikaite, J. Cvengroš, U. Piarulli, C. Gennari, Tetrahedron Lett. 2008, 49, 755-759; b) L. Pignataro, B. Lynikaite, J. Cvengroš, M. Marchini, U. Piarulli, C. Gennari, Eur. J. Org. Chem. 2009, 25392547.

[9] a) L. Pignataro, S. Carboni, M. Civera, R. Colombo, U. Piarulli, C. Gennari, Angew. Chem. 2010, 122, 6783-6787; Angew. Chem. Int. Ed. 2010, 49, 6633-6637; b) L. Pignataro, M. Boghi, M. Civera, S. Carboni, U. Piarulli, C. Gennari, Chem. Eur. J. 2012, 18, 1383-1400.

[10] See ref. [7f], and references therein.

[11] J. Meeuwissen, M. Kuil, A. M. van der Burg, A. J. Sandee, J. N. H. Reek, Chem. Eur. J. 2009, 15, 10272-10279.

[12] Use of this ligand in the hydrogenation of some substrates screened in this work had already been reported. For S1, see: a) ref. [11a]; for S3, see: b) M. T. Reetz, G. Mehler, A. Meiswinkel, T. Sell, Tetrahedron: Asymmetry 2004, 15, 2165-2167; c) ref. [14].

[13] Use of this ligand in the hydrogenation of some substrates screened in this work had already been reported. For S1, see: a) M. T. Reetz, G. Mehler, A. Meiswinkel (Studiengesellschaft Kohle MBH, Mülheim/Ruhr), DE-A 10027505.2, 2000; for S3, see: b) ref. [11a]; c) M. T. Reetz, G. Mehler, A. Meiswinkel, T. Sell, Tetrahedron Lett. 2002, 43, 7941-7943; d) ref. [27b].

[14] Absolute configuration of the product $\mathbf{P 2}$ was assigned by comparison of the sign of optical rotation with literature data, see: M. J. Burk, J. E. Feaster, W. A. Nugent, R. L. Harlow, J. Am. Chem. Soc. 1993, 115, 10125-10138.

[15] Absolute configuration of the product $\mathbf{P 4}$ was assigned by comparison of the sign of the optical rotation with literature data, see: M.-J. Kim, W.-H. Kim, K. Han, Y. K. Choi, J. Park, Org. Lett. 2007, 9, 1157-1159.

[16] H. Bernsmann, M. van den Berg, R. Hoen, A. J. Minnaard, G. Mehler, M. T. Reetz, J. G. de Vries, B. L. Feringa, J. Org. Chem. 2005, 70, 943-951.

[17] Z. Zhang, G. Zhu, Q. Jiang, D. Xiao, X. Zhang, J. Org. Chem. 1999, 64, 1774-1775.

[18] Absolute configuration of the product $\mathbf{P 5}$ was assigned by comparison of the sign of the optical rotation with literature data, see: Y.
Guo, G. Shao, L. Li, W. Wu, R. Li, J. Li, J. Song, L. Qiu, M. Prashad, F. Y. Kwong, Adv. Synth. Catal. 2010, 352, 1539-1553.

[19] Absolute configuration of the product $\mathbf{P 6}$ was assigned by comparison of the sign of the optical rotation with literature data, see: C. Pautigny, S. Jeulin, T. Ayad, Z. Zhang, J.-P. Genêt, V. Ratovelomanana-Vidal, Adv. Synth. Catal. 2008, 350, 2525-2532.

[20] For examples of ligand-ligand hydrogen-bonding interactions, see: a) B. Breit, W. Seiche, J. Am. Chem. Soc. 2003, 125, 6608-6609; b) W. Seiche, A. Schuschkowski, B. Breit, Adv. Synth. Catal. 2005, 347, 1488-1494; c) B. Breit, W. Seiche, Angew. Chem. 2005, 117, 1666-1669; Angew. Chem. Int. Ed. 2005, 44, 1640-1643; d) B. Breit, W. Seiche, Pure Appl. Chem. 2006, 78, 249-256; e) M. Weis, C Waloch, W. Seiche, B. Breit, J. Am. Chem. Soc. 2006, 128, 4188 4189; f) F. Chevallier, B. Breit, Angew. Chem. 2006, 118, 1629-1632 Angew. Chem. Int. Ed. 2006, 45, 1599-1602; g) Y. Liu, C. A. Sandoval, Y. Yamaguchi, X. Zhang, Z. Wang, K. Kato, K. Ding, J. Am Chem. Soc. 2006, 128, 14212-14213; h) M.-N. Birkholz, N. V. Dubrovina, H. Jiao, D. Michalik, J. Holz, R. Paciello, B. Breit, A. Börner, Chem. Eur. J. 2007, 13, 5896-5907; i) C. Waloch, J. Wieland, M Keller, B. Breit, Angew. Chem. 2007, 119, 3097-3099; Angew. Chem. Int. Ed. 2007, 46, 3037-3039; j) M.-N. Birkholz, N. V. Dubrovina, I. A. Shuklov, J. Holz, R. Paciello, C. Waloch, B. Breit, A Börner, Tetrahedron: Asymmetry 2007, 18, 2055-2060; k) T. Šmejkal, B. Breit, Organometallics 2007, 26, 2461-2464; 1) A. J. Sandee, A. M. van der Burg, J. N. H. Reek, Chem. Commun. 2007, 864-866; m) B. Schäffner, J. Holz, S. P. Verevkin, A. Börner, Tetrahedron Lett. 2008, 49, 768-771; n) B. Breit, Pure Appl. Chem. 2008, 80, 855-860; o) A. C. Laungani, B. Breit, Chem. Commun. 2008, 844-846; p) A. C. Laungani, J. M. Slattery, I. Krossing, B. Breit, Chem. Eur. J. 2008, 14, 4488-4502; q) F. W. Patureau, M. Kuil, A. J. Sandee, J. N. H. Reek, Angew. Chem. 2008, 120, 3224-3227; Angew. Chem. Int. Ed. 2008, 47, 3180-3183; r) M. de Greef, B. Breit, Angew. Chem. 2009, 121, 559-562; Angew. Chem. Int. Ed. 2009, 48, 551554 ; s) P.-A. R. Breuil, F. W. Patureau, J. N. H. Reek, Angew. Chem. 2009, 121, 2196-2199; Angew. Chem. Int. Ed. 2009, 48, 2162-2165; t) J. Meeuwissen, A. J. Sandee, B. de Bruin, M. A. Siegler, A. L. Spek, J. N. H. Reek, Organometallics 2010, 29, 2413-2421; u) J. Wieland, B. Breit, Nat. Chem. 2010, 2, 832-837; v) D. Fuchs, G. Rousseau, L. Diab, U. Gellrich, B. Breit, Angew. Chem. 2012, 124, 2220 2224; Angew. Chem. Int. Ed. 2012, 51, 2178-2182.

[21] For examples of ligand-substrate hydrogen-bonding interactions, see: a) D. B. Grotjahn, Chem. Eur. J. 2005, 11, 7146-7153; b) I. Usui, S. Schmidt, M. Keller, B. Breit, Org. Lett. 2008, 10, $1207-$ 1210 ; c) S. Das, C. D. Incarvito, R. H. Crabtree, G. W. Brudvig, Science 2006, 312, 1941-1943; d) T. Šmejkal, B. Breit, Angew. Chem. 2008, 120, 317-321; Angew. Chem. Int. Ed. 2008, 47, 311-315; e) T. Šmejkal, B. Breit, Angew. Chem. 2008, 120, 4010-4013; Angew. Chem. Int. Ed. 2008, 47, 3946-3949; f) L. Diab, T. Šmejkal, J. Geier, B. Breit, Angew. Chem. 2009, 121, 8166-8170; Angew. Chem. Int. Ed. 2009, 48, 8022-8026; g) ref. [20s]; h) T. Šmejkal, D. Gribkov, J. Geier, M. Keller, B. Breit, Chem. Eur. J. 2010, 16, 2470-2478; i) P. Fackler, C. Berthold, F. Voss, T. Bach, J. Am. Chem. Soc. 2010, 132 15911-15913; j) ref. [20v].

[22] M. van den Berg, B. L. Feringa, A. J. Minnaard in Handbook of Homogeneous Hydrogenation (Eds.: J. G. de Vries, C. J. Elseiver), Wiley-VCH, Weinheim, 2007, pp. 995-1027.

[23] a) N. V. Dubrovina, I. A. Shuklov, M.-N. Birkholz, D. Michalik, R. Paciello, A. Börner, Adv. Synth. Catal. 2007, 349, 2183-2187; b) I. A. Shuklov, N. V. Dubrovina, E. Barsch, R. Ludwig, D. Michalik, A. Börner, Chem. Commun. 2009, 1535-1537.

[24] For the synthesis of these substrates, see ref. [9b], and references therein.

[25] Absolute configuration of the product P4-O was assigned by comparison of the sign of optical rotation with literature data, see: H. M. C. Ferraz, G. G. Bianco, C. C. Teixeira, L. H. Andrade, A. L. M. Porto, Tetrahedron: Asymmetry 2007, 18, 1070-1076.

[26] For key papers on the mechanism of rhodium-catalyzed asymmetric hydrogenation, see: a) J. Halpern, Science 1982, 217, 401-407; b) C. R. Landis, J. Halpern, J. Am. Chem. Soc. 1987, 109, 1746- 
1754; c) C. R. Landis, P. Hilfenhaus, S. Feldgus, J. Am. Chem. Soc. 1999, 121, 8741-8754; d) S. Feldgus, C. R. Landis, J. Am. Chem. Soc. 2000, 122, 12714-12727; e) C. R. Landis, S. Feldgus, Angew. Chem. 2000, 112, 2985-2988; Angew. Chem. Int. Ed. 2000, 39, 2863-2866; f) R. Giernoth, H. Heinrich, N. J. Adams, R. J. Deeth, J. Bargon, J. M. Brown, J. Am. Chem. Soc. 2000, 122, 12381-12382; g) H. Heinrich, R. Giernoth, J. Bargon, J. M. Brown, Chem. Commun. 2001, 1296-1297; h) I. D. Gridnev, T. Imamoto, Acc. Chem. Res. 2004, 37, 633-644; i) I. D. Gridnev, T. Imamoto, Chem. Commun. 2009, 7447 7464.

[27] I. D. Gridnev, E. Alberico, S. Gladiali, Chem. Commun. 2012, 48, 2186-2188.

[28] a) M. T. Reetz, A. Meiswinkel, G. Mehler, K. Angermund, M. Graf, W. Thiel, R. Mynott, D. G. Blackmond, J. Am. Chem. Soc. 2005, 127, 10305-10313; b) I. D. Gridnev, C. Fan, P. G. Pringle, Chem. Commun. 2007, 1319-1321; c) L. Schiaffino, G. Ercolani, J. Phys. Org. Chem. 2011, 24, 257-261; d) E. Alberico, W. Baumann, J. G. de Vries, H.-J. Drexler, S. Gladiali, D. Heller, H. J. W. Henderickx, L. Lefort, Chem. Eur. J. 2011, 17, 12683-12695; e) S. Gladiali, E. Alberico, I. Gridnev in Innovative Catalysis in Organic Synthesis: Oxidations, Hydrogenations, and $C-X$ Bond Forming Reactions (Ed.: P. G. Andersson), Wiley-VCH, Weinheim, 2012, pp. 105-129.
[29] Already used for calculations on analogous rhodium complexes of PhthalaPhos ligands, see ref. [9b].

[30] All DFT calculations were performed by using Jaguar version 7.7 (Schrödinger, LLC, New York). For DFT calculations of supramolecular bidentate Rh complexes, see refs. [9] and [20s].

[31] All calculations were run by using the Schrödinger suite of programs (http://www.schrodinger.com) through the Maestro graphical interface. Monte Carlo/Energy Minimization (MC/EM) conformational search (see ref. [32]) was performed within the framework of MacroModel version 9.7 (Schrödinger, LLC, New York) by using the MacroModel implementation of the Amber all-atom force field (denoted AMBER*, see ref. [33a]) and the $\mathrm{CHCl}_{3} \mathrm{~GB} / \mathrm{SA}$ solvation model (see ref. [33b]).

[32] G. Chang, W. C. Guida, W. C. Still, J. Am. Chem. Soc. 1989, 111, 4379-4386.

[33] a) S. J. Weiner, P. A. Kollman, D. T. Nguyem, D. A. Case, J. Comput. Chem. 1986, 7, 230-252; b) W. C. Still, A. Tempczyk, R. C. Hawley, T. Hendrickson, J. Am. Chem. Soc. 1990, 112, 6127-6129.

Received: March 27, 2012 Revised: May 22, 2012 Published online: June 19, 2012 